\title{
过渡金属催化碳二亚胺环化的研究进展
}

\author{
张 震*,a畅温旭 $b$ \\ ( ${ }^{a}$ 烟台大学化学化工学院 山东烟台 264005) \\ ( $b$ 中国农业大学理学院 北京 100193)
}

\begin{abstract}
摘要 碳二亚胺是合成含氮分子最有效的前体之一. 过渡金属催化的碳二亚胺环化反应已成为合成杂环产物的有效方 法, 并引起了合成化学和药物化学家的极大关注. 近些年发表的大量成果证明了该合成方法在现代有机合成中的重要 性. 总结了该领域在过去十年中的研究进展及一些开拓性的工作. 根据不同的环化机理，从三部分归纳和讨论了从碳 二亚胺到系列杂环分子的合成方法，主要包括由亲核过程引发的串联环化、基于碳二亚胺对环金属中间体插入过程的 环化和含不饱和体系的碳二亚胺参与的协同环化.
\end{abstract}

关键词＼cjkstart碳二亚胺；过渡金属催化；环化；杂环；杂累积双烯

\section{Progress in Transition-Metal-Catalyzed Cyclization of Carbodiimides}

\author{
Zhang, Zhen ${ }^{*, a} \quad$ Chang, Wenxu ${ }^{b}$ \\ ( ${ }^{a}$ College of Chemistry and Chemical Engineering, Yantai University, Yantai, Shandong 264005) \\ ( ${ }^{b}$ Department of Applied Chemistry, China Agricultural University, Beijing 100193)
}

\begin{abstract}
Carbodiimide is one of the most efficient precursors to the synthesis of N-containing molecules. Transition-metalcatalyzed cyclization of carbodiimides has become a powerful approach to heterocyclic products, and attracts considerable attention from synthetical and pharmaceutical chemists. The significant amount of documents that were published during the last years proves the importance of this approach in modern organic synthesis. The development of this field over last decade and some pioneering work are summarized. An array of synthetic methods for privileged heterocycles from carbodiimides are presented according to mechanically distinctive processes: cascade cyclization initiated by nucleophilic process, catalytic cyclization via the insertion of carbodiimides into metal-cycle intermediates and annulation of tethered carbodiimides with unsaturated systems.

Keywords carbodiimide; transition-metal-catalysis; cyclization; heterocycle; heterocumulene
\end{abstract}

碳二亚胺，因其独特的累积 $\mathrm{C}=\mathrm{N}$ 结构和易于制备 的特性，已成为合成多种含氮化合物的有效前体 ${ }^{[1-2]}$. 在 过去的十年中，随着有机金属化学的蓬勃发展，过渡金 属催化的碳二亚胺环化反应也取得了飞速发展. 以碳二 亚胺为底物的催化环化反应, 可以快速高效构建多种广 泛存在于天然产物和生物活性分子中的杂环骨架(如苯 并咪唑、喹唑啉和氨基喹唑啉酮), 引起了合成化学家和 药物化学家们的广泛关注. 然而, 对于这一重要领域的 研究进展, 近些年仅有少数综述涉及 ${ }^{[2 \mathrm{~d}-2 \mathrm{e}, 3]}$, 并没有专 门的文章对其进行系统的总结和讨论. 直到最近, 席振 峰和张文雄小组 ${ }^{[4]}$ 根据氮杂环类型分类, 系统地综述了 碳二亚胺在氮杂环化合物合成中的应用. 虽然该综述囊
括了过去近四十年中碳二亚胺环化的大多数例子, 但鉴 于过渡金属催化反应在有机合成领域的重要应用价值 以及涉及的催化机理对分析和设计新型杂环分子具有 重要指导意义, 很有必要针对过渡金属催化碳二亚胺环 化这一重要领域, 进行详细归纳和总结, 尤其对近些年 发展的催化反应机理进行分析和讨论.

作者结合自己在碳二亚胺化学领域的研究工作, 在 该文中总结和讨论了该领域过去十年中的研究进展和 一些开创性、里程碑式的工作. 为了帮助研究者更好地 了解碳二亚胺的反应特点和环化类型, 并基于此能更好 地设计需要的杂环分子, 本文将重点讨论催化环化的机 理，并根据不同的环化过程进行分类，主要包括三部分:

* Corresponding author. E-mail: zhangz@ytu.edu.cn

Received October 15, 2020; revised November 5, 2020; published online December 4, 2020.

Project supported by the Doctoral Scientific Research Foundation of Yantai University (No. HY19B07).

烟台大学博士科研启动基金(No. HY19B07)资助项目. 
亲核加成过程引发的串联环化、基于碳二亚胺对环金属 中间体插入过程的环化和含不饱和体系的碳二亚胺参 与的协同环化. 每个部分将根据底物的结构特点进一步 细分讨论(Scheme 1).

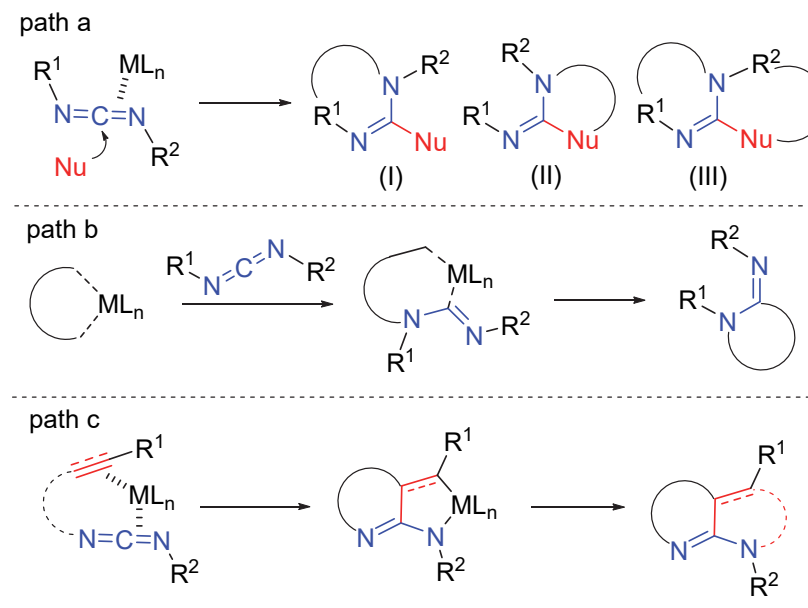

图式 1 过渡金属催化碳二亚胺环化的不同反应路径

Scheme 1 Transition-metal-catalyzed cyclization of carbodiimides via distinctive paths

\section{1 亲核加成过程引发的串联环化}

由于碳二亚胺中心碳原子的亲电性, 由亲核加成引 发的催化环化已成为构建杂环化合物的便捷方式. 从环 化方式来看，亲核加成形成的中间体可以在过渡金属催 化下与碳二亚胺或亲核试剂中的官能团继续反应实现 环化. 因此, 本节根据参与环化的位点不同, 分为碳二 亚胺中官能团参与的环化反应、亲核试剂中官能团参与 的环化反应和两底物所含官能团均参与的环化反应三 类.

\section{1 碳二亚胺中官能团参与的环化反应}

该过程中，亲核加成产生的中间体，可与碳二亚胺 上的官能团通过后续的偶联、插入及加成等途径实现环 化(Scheme 2). 2009 年, 包伟良课题组 ${ }^{[5]}$ 报道了一种以邻 卤代芳基碳二亚胺为底物的铜催化加成/环化反应. 通 过此反应, 可以以中等到优秀的产率合成多种在生物学 上具有重要意义的 2-杂苯并咪唑类化合物. 反应机理如 Scheme 3 所示, 首先亲核试剂与邻卤代碳二亚胺 1 反应 得到中间体 2 , 然后通过铜催化的分子内 $\mathrm{C}-\mathrm{N}$ 偶联关 环形成产物, 该过程类似于已报道的铜催化的胺化过 程 ${ }^{[6]}$. 在后续的研究中, 该课题组发现当使用无卤素取 代的碳二亚胺时, 在氧化剂存在下也可以合成取代的 2氨基苯并咪唑 ${ }^{[7]}$. 虽然尚不清楚该反应的详细机理, 作 者推测铜催化的芳环 $\mathrm{C}-\mathrm{H}$ 键活化和中间体 6 被氧化成 $\mathrm{Cu}-\mathrm{N}$ 复合物 7 的过程, 可能是整个环化反应的关键步
骤(Scheme 4).

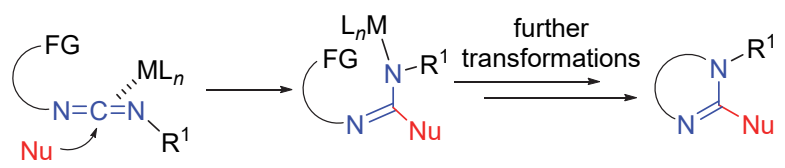

图式 2 碳二亚胺中官能团参与环化反应的基本策略 Scheme 2 Strategy of cascade cyclization with group in carbodiimide

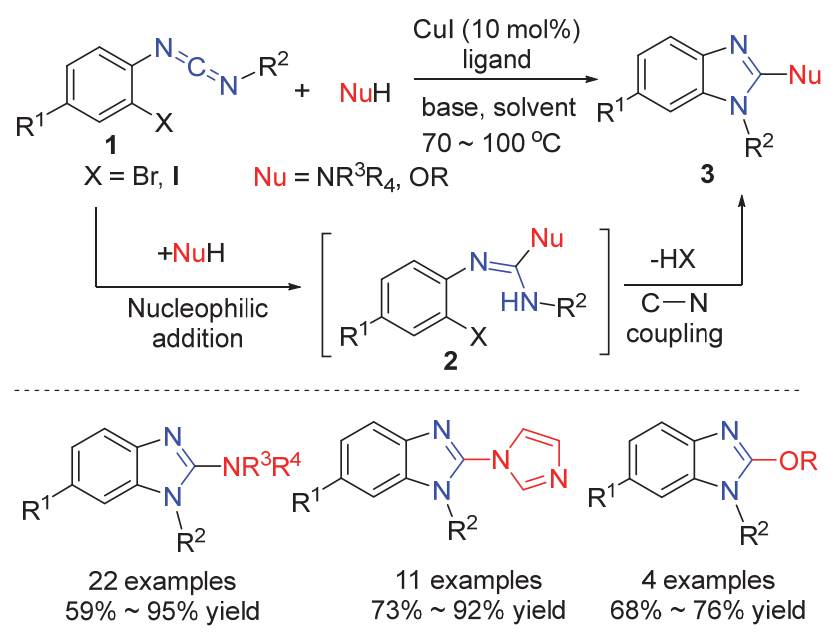

图式 $3 \mathrm{Cu}(\mathrm{I})$ 催化的串联环化反应合成 2-杂苯并咪唑

Scheme $3 \mathrm{Cu}(\mathrm{I})$-catalyzed cascade cyclization to synthesize 2-heterobenzimidazoles

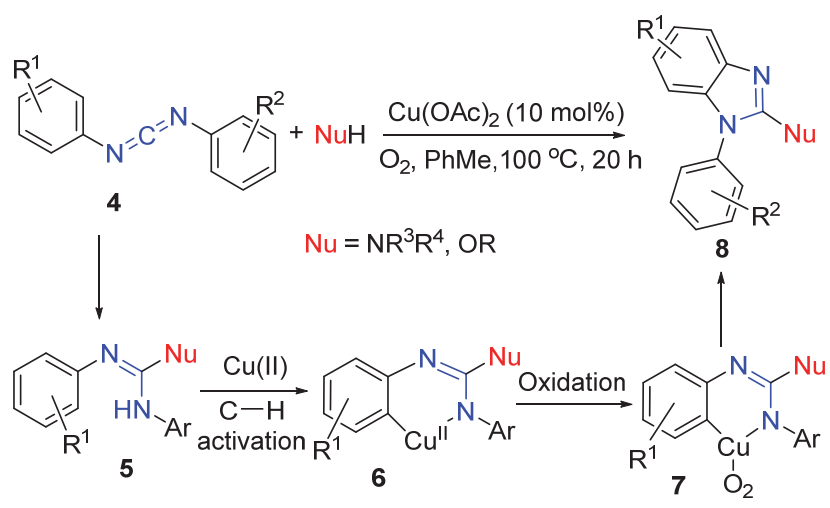

图式 $4 \mathrm{Cu}(\mathrm{II})$ 催化的串联环化反应合成苯并咪唑或喹唑啉 Scheme $4 \mathrm{Cu}(\mathrm{II})$-catalyzed cascade cyclization to synthesize benzimidazoles or quinazolines

当以炔基碳二亚胺为底物时, 分子中 $\mathrm{C} \equiv \mathrm{C}$ 会参与 后续的亲核环化过程. 2009 年, 丁明武课题组 ${ }^{[8]}$ 报道了 $\operatorname{Ag}(\mathrm{I})$ 催化炔烃碳二亚胺的分子间加成、环化反应，高效 地合成了 $N$-羧酰亚胺类化合物. 该反应具有优异的区 域选择性，亲核加成产生的中间体 9 通过与芳环相连氮 原子的亲核环化专一地生成吲哚衍生物 10 , 而另一端 氮原子亲核进攻生成喹唑啉衍生物 12 的过程则没有发 生(Scheme 5). 
<smiles>[R1]c1ccc(N=C=NBr)c(C#CCc2ccccc2)c1</smiles><smiles>CC(C)(C)OC(=O)OC(N)CN</smiles>
$(5 \mathrm{~mol} \%), \mathrm{Nu}=\mathrm{NR}^{3} \mathrm{R}^{4}, \mathrm{OR}$

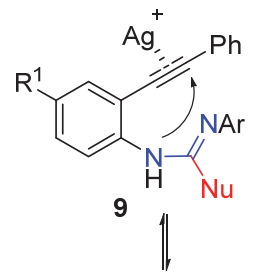<smiles>[R1]c1ccc2c(c1)cc(-c1ccccc1)n2/C(=N\[In])[N+]#N</smiles>
$68 \% \sim 93 \%$ yield

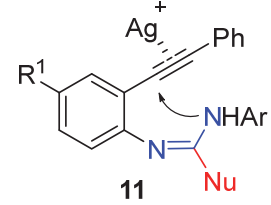<smiles>[R1]c1ccc2c(c1)/C(=C/P)N([Bi])C(N)=N2</smiles>

12

图式 $5 \mathrm{Ag}(\mathrm{I})$ 催化的区域选择性环化合成吲哚 $N$-羧酰亚胺或 $N$-羧酰亚胺

Scheme 5 Ag(I)-catalyzed regioselective cyclization to synthesize indole $N$-carboximidamides or $N$-carboximidoates

最近，吕新课题组 ${ }^{[9]}$ 利用炔基碳二亚胺开发了一 种新颖的 “一锅法” 合成多取代的 2-咪唑基咪唑、2-
吡唑基咪唑和 2-吲唑基咪唑的多组分反应. 在铜催 化下，以 $N$-炔丙基碳二亚胺、唑、多聚甲醛或亚胺作 为起始原料, 通过连续的加成、偶联及环化等过程, 可以方便有效地将多种氨基乙基或羟乙基连接的 2偶氮基咪唑衍生物进行快速组装(Scheme 6). 其过程 中首先唑与碳二亚胺亲核加成生成胍 14 , 随后在 $\mathrm{Cu}$ 的作用下与醛或亚胺正离子发生亲核加成得到中间 体 15, 最后经过氨基与炔烃的亲核环化得到目标产 物. 此外，作者发现对于含有邻碘芳基的产物可以通 过铜催化的分子内 $\mathrm{C}-\mathrm{H}$ 芳基化进一步转化为咪唑并 $[1,2 c]$ 咪唑并 $[1,2 a]$ 喹唑啉衍生物.

一氧化碳 $(\mathrm{CO})$ 是一种重要的 $\mathrm{C} 1$ 原料, 过渡金属催 化的 $\mathrm{CO}$ 插入反应已成为一种获得羰基化合物的有效且 有价值的方法 ${ }^{[10]} .2010$ 年, Alper 小组 ${ }^{[11]}$ 首次结合碳二亚 胺的亲核加成和 $\mathrm{CO}$ 插入过程, 发展了 $\mathrm{Pd}$ 催化邻碘芳基 碳二亚胺、仲胺和 CO (0.69 MPa) 的三组分反应，合成一 系列 2-杂喹唑啉-4(3H)-酮衍生物. 催化循环中, 原位生 成的胍 16 经氧化加成得到中间体 17 , 然后 $\mathrm{CO}$ 插入 $\mathrm{Pd}-\mathrm{C}$ 键中形成芳酰基碘化钯络合物 18, 再通过配体交 换和还原消除, 再生 $\operatorname{Pd}(0)$ 催化剂并释放目标产物 (Scheme 7).<smiles>[Y]CCc1c([R])nc(-n2cnc3ccccc32)n1[R]</smiles>

图式 $6 \mathrm{Cu}(\mathrm{I})$ 催化的催化一锅合成 2-偶氮咪坐衍生物

Scheme $6 \mathrm{Cu}(\mathrm{I})$-catalyzed one-pot synthesis of 2-azolylimidazole derivatives

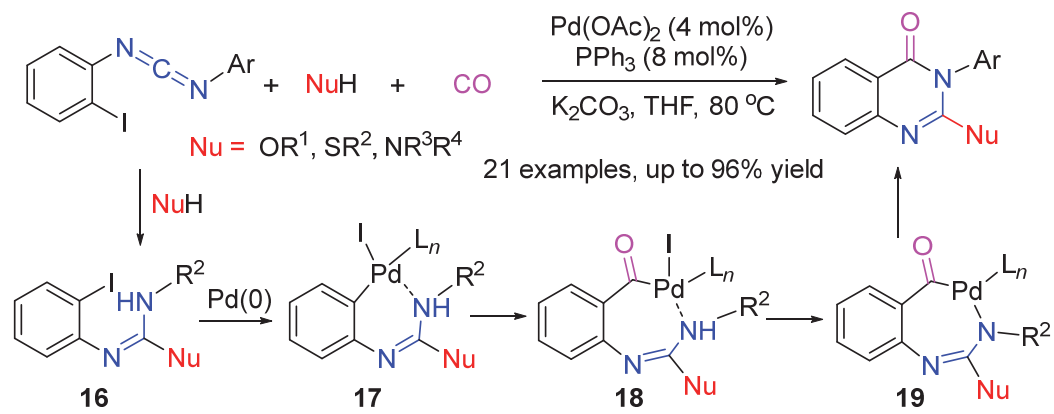

图式 $7 \mathrm{Pd}$ 催化串联加成/环羰基化反应合成 2-杂喹唑啉-4(3H)-酮

Scheme 7 Tandem Pd-catalyzed addition/cyclocarbonylation to synthesize 2-heteroquinazolin-4(3H)-ones 
异腈 $(\mathrm{CN}-\mathrm{R})$ 作为 $\mathrm{CO}$ 的等电子体, 也是一种重要 的 $\mathrm{C} 1$ 原料，已被广泛用于有机合成中[12]. 受到 Alper 等 结合 $\mathrm{CO}$ 插入过程的启发, 吴劼课题组 ${ }^{[13]}$ 报道了一种 $\mathrm{Pd}$ 催化的碳二亚胺、异腈和胺或醇的三组分反应，制备了 一系列喹唑啉-4 $(3 H)$-亚胺类化合物(Scheme 8, a). 该反 应机理与 $\mathrm{CO}$ 的环化反应类似, 催化循环中异腈可替代 $\mathrm{CO}$ 实现插入过程. 除胺和醇外, 该课题组在后续工作 中对亚磷酸酯作为亲核试剂进行了研究, 结果表明在 $1,1^{\prime}$-双 (二苯基膦)二茂铁(DPPF)作为配体, $\mathrm{FeCl}_{3}$ 为添加 剂的条件下, Pd 催化的碳二亚胺、异腈和亚磷酸酯的反 应同样具有较好的反应性, 以中等到较好的产率得到膦 酰化喹唑啉化合物(Scheme 8, b $)^{[14]}$. 这一系列工作有力 地证明了碳二亚胺在杂环分子构建中的重要价值.

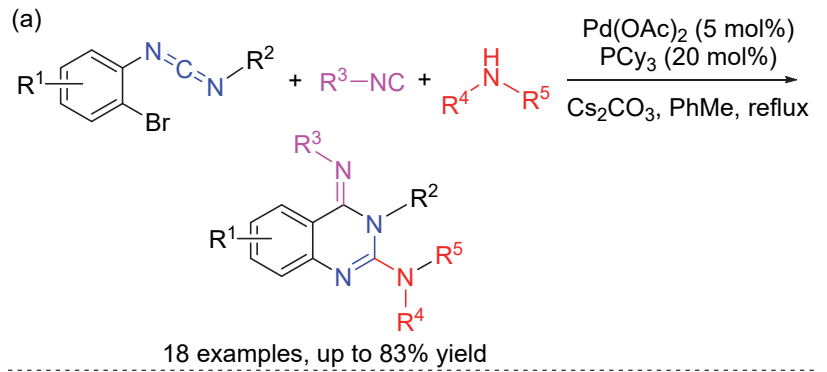

(b)

$$
\text { (15 examples, up to } 78 \% \text { yield }
$$

图式 $8 \mathrm{Pd}$ 催化三组分反应合成喹唑啉-4 $(3 H)$-亚胺和 4-亚氨 基-3,4-二氢喹唑啉-2-基膦酸酯

Scheme 8 Pd-catalyzed three-component reaction to synthesize quinazolin-4(3H)-imines and 4-imino-3,4-dihydroquinazolin-2ylphosphonates

\section{2 亲核试剂中官能团参与的环化反应}

经过亲核加成后，所得中间体可以进一步与亲核试 剂中的活性基团反应，经过偶联、插入及取代等过程， 实现杂环的构建 (Scheme 9). 该策略中与上一种亲核环 化模式相比，碳二亚胺的取代基更易于修饰，在复杂环 合分子合成方面具有更大的优势.

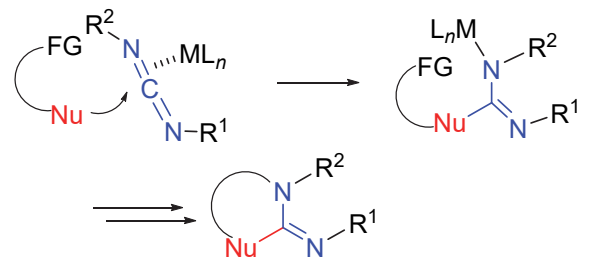

图式 9 亲核试剂中官能团参与环化反应的基本策略 Scheme 9 Strategy of cascade cyclization with the functional group in nucleophile

基于此策略，1998 年, Alper 课题组 ${ }^{[15]}$ 首次利用 $\operatorname{Pd}(0)$ 催化碳二亚胺与乙烯基环氧乙烷的环加成反应合 成了一系列 4-乙烯基-1,3-噁唑啉-2-亚胺衍生物，反应收 率较高, 选择性较好. 作者推测, 该反应可能首先通过 氧化加成产生两性离子钯中间体 20, 随后再与非对称 碳二亚胺发生亲核加成生成两种中间体 21 和 22 . 由于 取代基的空间位阻，碳二亚胺中氮阴离子的亲核进攻倾 向在位阻小的一端进行，表现出较好的区域选择性 (Scheme 10). 此外, 作者研究发现在手性膦配体存在 下，该反应还显示出高对映选择性.

在之前的工作基础上，该课题组 ${ }^{[16]}$ 将环化的底物 扩展至 2-乙烯基氮丙啶和 2-乙烯基吡咯烷，分别形成了 五元咪唑烷亚胺和七元环芳基胍(Scheme 11). 然而遗憾 的是, 相对于五元环产物, 七元环反应的对映选择性较 差. 作者认为主要有两个因素导致: 其一，生成的中间 体 23 和 24 可以快速地相互转化; 其二, 与形成五元环 相比，七元环反应中分子内亲核进攻距离较长，分子柔 性增加, 难以实现高选择性的亲核环化(Scheme 11, b).

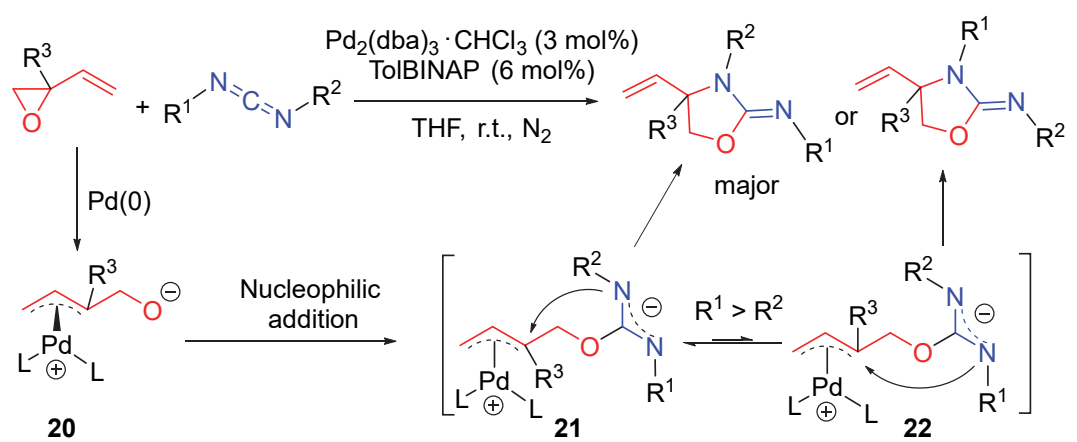

图式 $10 \operatorname{Pd}$ 催 $\operatorname{Pd}(0)$ 催化的乙烯基氧杂环戊烷与碳二亚胺的环加成反应

Scheme $10 \operatorname{Pd}(0)$-catalyzed cycloaddition of vinyloxiranes with carbodiimides 


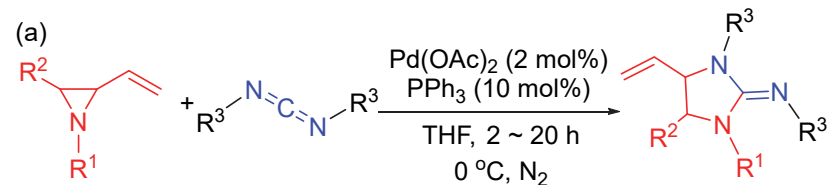

(b)
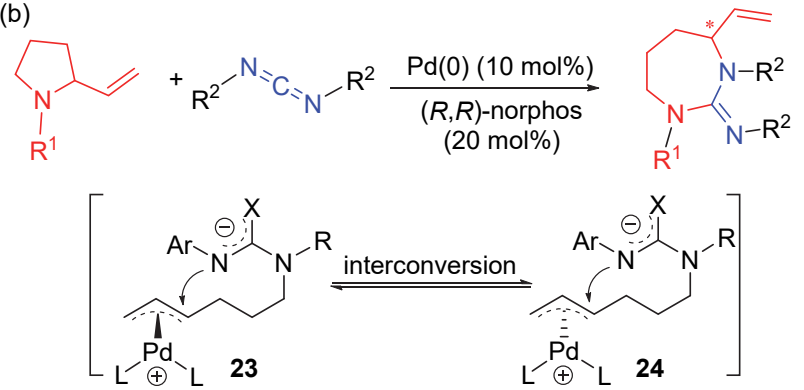

图式 $11 P d$ 催化碳二亚胺环化合成 2-乙烯基氮丙啶或 2-乙烯 基吡咯烷

Scheme 11 Pd-catalyzed cyclization to synthesize 2-vinylaziridines or 2-vinylpyrrolidines with carbodiimides

除了过渡金属 $\mathrm{Pd}$ 催化过程, 席婵娟课题组 ${ }^{[17]}$ 和包 伟良课题组 ${ }^{[18]}$ 分别独立报道了 $\mathrm{Cu}(\mathrm{I})$ 催化碳二亚胺与邻 卤代苯酚和邻卤代苯胺的亲核环化反应, 以中等至优秀 的产率合成苯并噁唑和苯并咪唑衍生物 (Scheme 12). 此类反应与前文所述的邻卤代芳基碳二亚胺与亲核试 剂的反应过程相似, 但由于亲核试剂中的杂原子参与了 环化, 该策略可以制备更加多样的杂环体系. 值得注意 的是, 对于非对称的碳二亚胺, 反应也表现出较好的区 域选择性.

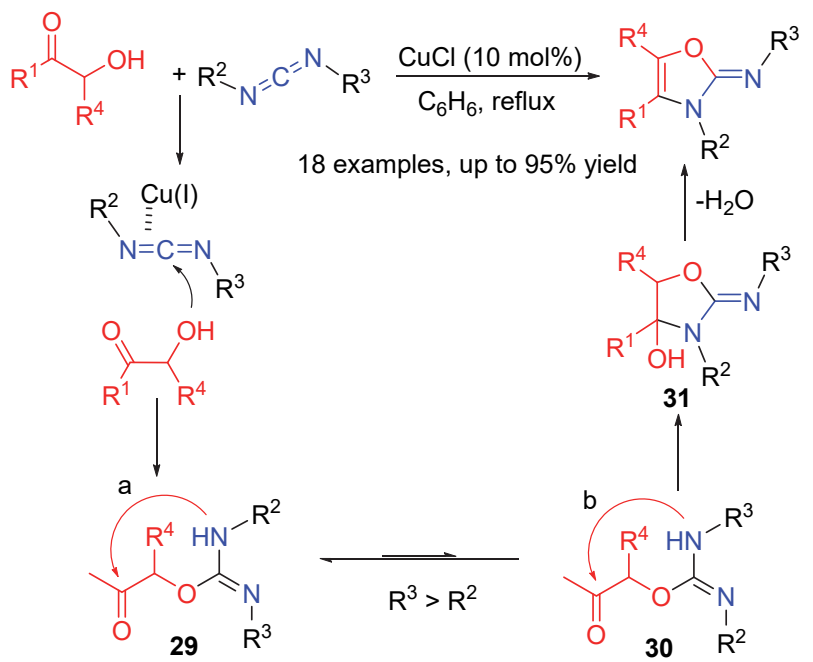

图式 12 无配体 $\mathrm{Cu}(\mathrm{I})$ 催化邻卤代苯酚或邻卤代苯胺与碳二亚 胺的环化反应

Scheme 12 Ligand-free $\mathrm{Cu}(\mathrm{I})$-catalyzed cascade reaction of $o$-halophenols or $o$-haloanilines with carbodiimides

2018 年, Kaeobamrung 小组 ${ }^{[19]}$ 报道一种 $\mathrm{Cu}(\mathrm{I})$ 促进的 2-碘苯甲酸和对称碳二亚胺的串联环化反应. 通过连续
的亲核加成和环化, 得到相应的喹唑啉二酮衍生物. 反 应中, $\mathrm{Cu}_{2} \mathrm{O}$ 的加入量对于减少酰胺副产物至关重要. 根 据之前的工作和控制实验, 作者提出了反应机理 (Scheme 13). 首先, 在 $\mathrm{Cu}_{2} \mathrm{O}$ 的辅助下, 羧酸与碳二亚胺 发生亲核反应形成中间体 25 , 再经过重排生成 $N$-酰嫝 中间体，最后通过 $\mathrm{Cu}(\mathrm{I})$ 催化的分子内 $\mathrm{C}-\mathrm{N}$ 键构建得到 目标产物. 此过程中存在可能竞争反应, 即 $N$-酰基脲经 过消除生成酰胺副产物 28, 因此为了减少副反应, 需要 用到化学计量的 $\mathrm{Cu}_{2} \mathrm{O}$.

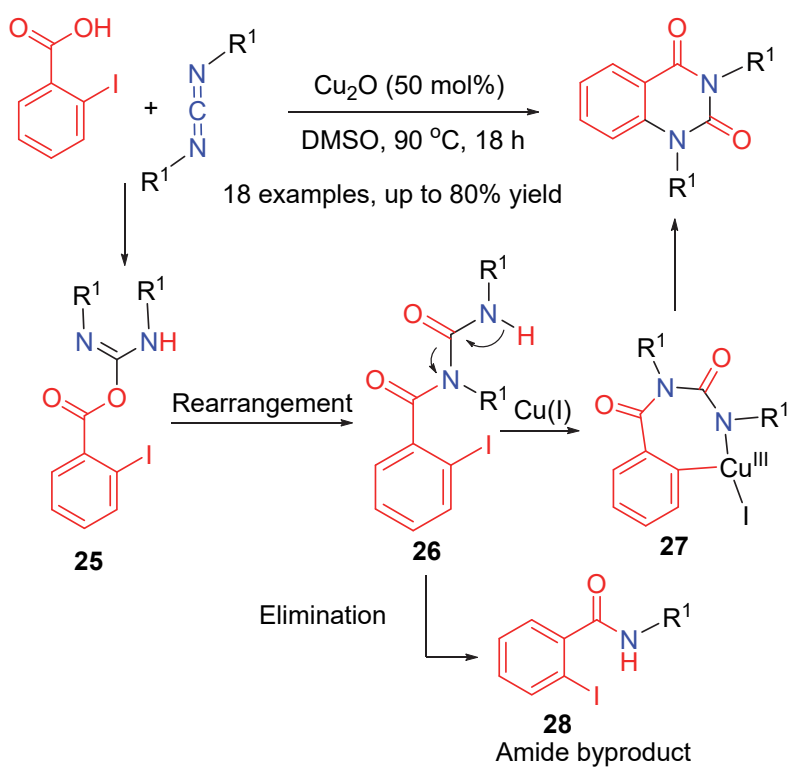

图式 $13 \mathrm{Cu}$ 催化碳二亚胺与苯甲酸衍生物的多米诺反应 Scheme $13 \mathrm{Cu}$-catalyzed domino reaction of carbodiimides and benzoic acid derivatives

$\mathrm{Hahn}$ 等 ${ }^{[20]}$ 报道了另一个涉及 $\mathrm{Cu}(\mathrm{I})$ 催化亲核环化的 反应，作者以 $\alpha$-羟基酮为亲核试剂，经过亲核加成和环 化以中等至较高产率得到多取代的 2-亚氨基-1,3-噁唑 啉衍生物. 此反应机理是由羟基氧亲核进攻非对称碳二 亚胺中心碳，加成得到中间体 29 和 30 . 由于较大 $\mathrm{R}^{3}$ 基 才的空间排斥，通过路径 a 关环更为有利，也因此使反 应具有较好的区域选择性. 最后, 高温条件下脱水, 得 到所需的产物 2-亚氨基-噁唑啉(Scheme 14).

亲核加成与 $\mathrm{CO}$ 插入过程的结合不仅可以在第一种 亲核环化策略中应用，类似的方法也可以应用到游离碳 二亚胺的多组分反应中. Alper 等 ${ }^{[21]}$ 在前期工作基础上, 发展了 $\mathrm{Pd}$ 催化的邻二碘苯胺和碳二亚胺的环羰基化反 应. 在高压的 $\mathrm{CO}(2.07 \mathrm{MPa})$ 气氛下, 高收率地获得喹 唑啉-4(3H)-酮衍生物. 反应中, 首先通过亲核加成原位 生成胍, 再经过 $\mathrm{Pd}$ 催化的羰基化和环化生成最终产物 (Scheme 15). 


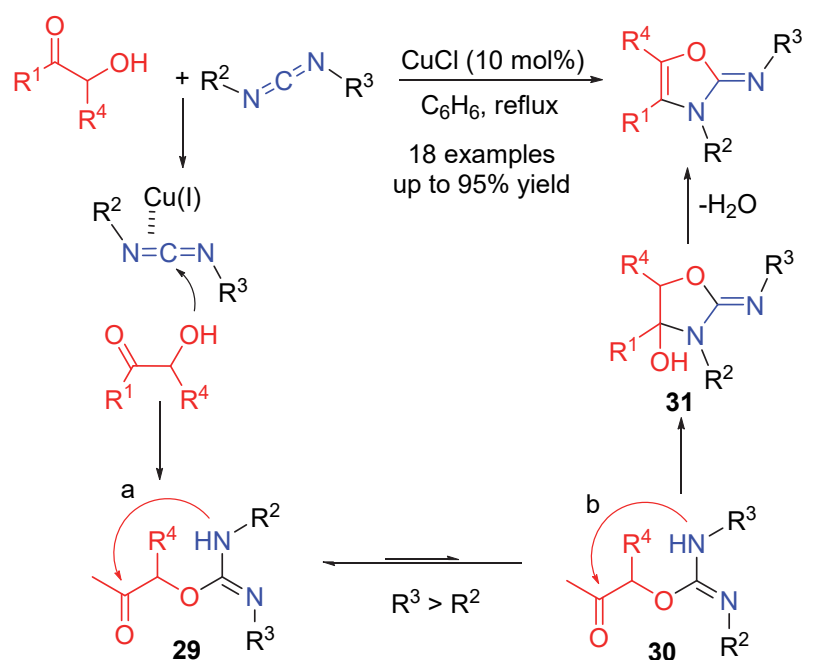

图式 $14 \mathrm{Cu}(\mathrm{I})$ 催化 $\alpha$-羟基酮和碳二亚胺的多米诺反应合成 2亚氨基-1,3-噁唑啉

Scheme $14 \mathrm{Cu}(\mathrm{I})$-catalyzed domino reaction of $\alpha$-hydroxyketones and carbodiimide to synthesize 2-imino-1,3-oxazoline

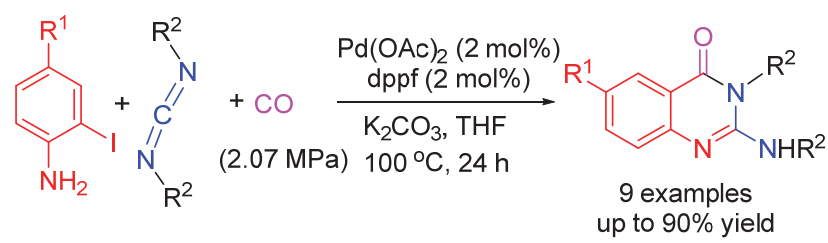

图式 $15 \mathrm{Pd}$ 邻碘苯胺与碳二亚胺的环羰基化反应 Scheme 15 Pd-catalyzed cyclocarbonylation of $o$-iodoanilines with carbodiimides

氨基酯化合物由于结构中胺的亲核性和酯羰基的 亲电性，是合成环化产物的重要合成子. 近年来，该系 列分子已被广泛用于碳二亚胺的亲核环化反应，通过催
化胍化或酰胺化反应构建环氧代胍衍生物。例如, 2015 年, 席振峰和张文雄小组 ${ }^{[2]}$ 报道了一种 $\mathrm{Zn}(\mathrm{OTf})_{2}$ 催化的 环化反应, 利用氨基酸盐酸盐与碳二亚胺发生连续的亲 核环化，得到 2-氨基-1H-咪唑-5(4H)-酮衍生物。该方法 首次将铵盐应用于胍化反应，通过对重要中间体的分离 和表征，作者提出了一种可能的机理：首先，与氨基酸 酯络合的催化剂通过与碳二亚胺氮原子配位将其活化; 随后中间体 33 氨基端亲核进攻碳二亚胺中心碳原子, 加成得到中间体 34; 然后发生分子内亲核酰胺化生成 中间体 35 和产物; 最后经过配体交换完成催化循环 (Scheme 16). 作者还进一步考察了具有类似反应特点 的 2-氨基苯甲酸酯的反应活性，该底物在 $\mathrm{Zn}(\mathrm{OTf})_{2}$ 的催 化下, 可以高效地生成一系列六元 2-氨基喹唑啉-4(3H)酮类化合物(Scheme 17, a $)^{[22]}$.

此外，近几年还发展了一些稀土金属络合物催化 2氨基苯甲酸酯与碳二亚胺的亲核环化反应. 最近姚英明 和赵蓓小组 ${ }^{[23]}$ 报道了一例 $\mathrm{La}\left[\mathrm{N}(\mathrm{TMS})_{2}\right]_{3}$ 催化的环化反 应，在不加入溶剂的情况下可以高产率地合成各种取代 的 2-氨基喹唑啉-4(3H)-酮类化合物, 具有良好的底物适 用性(Scheme 17, b). 随后, Panda 研究小组 ${ }^{[24]}$ 利用相对 丰富且价格低廉的钛(IV)配合物，在温和条件下也成功 地实现了这种环化反应，且同样显示出高转化率和较好 的官能团耐受性(Scheme 17, c).

2017 年, 席振峰和张文雄小组 ${ }^{[25]}$ 报道了一例铜催 化的碳二亚胺、炔烃和二芳基碘鎓盐的级联三组分环氧 化反应. 这种 $[2+2+2]$ 环化过程可以一次构建两个 C $\mathrm{C}$ 键和一个 $\mathrm{C}-\mathrm{N}$ 键, 为合成喹啉衍生物提供了一种新 颖的方法. 作者通过详细密度泛函理论(DFT)计算, 提 出了可能的反应机理: 在 $\mathrm{Cu}$ 的催化下, 碳二亚胺与二

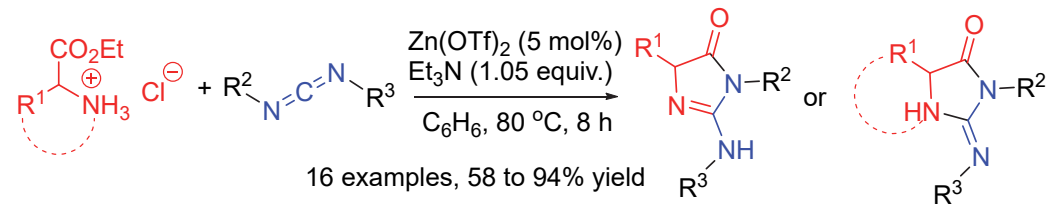

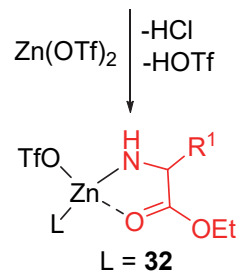

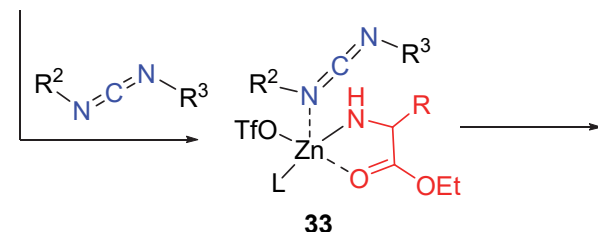

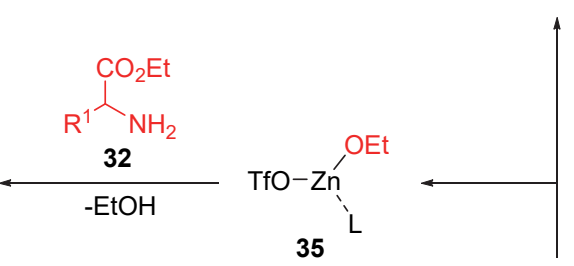

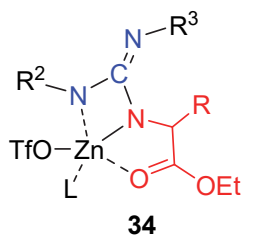

图式 $16 \mathrm{Zn}(\mathrm{OTf})_{2}$ 催化的氨基酸酯和碳二亚胺的环胍化/酰胺化

Scheme $16 \mathrm{Zn}(\mathrm{OTf})_{2}$-catalyzed guanylation/amidation of amino acid esters and carbodiimides 
<smiles>[R]N=C=N[R]C(=O)OCC</smiles>

(a) Zhang and Xi's work $\mathrm{Zn}(\mathrm{OTf})_{2}(5 \mathrm{~mol} \%), \mathrm{C}_{6} \mathrm{H}_{6}, 80^{\circ} \mathrm{C}, 8 \mathrm{~h}$

(b) Zhao's work $\mathrm{La}\left[\mathrm{N}(\mathrm{TMS})_{2}\right]_{3}(5 \mathrm{~mol} \%)$, neat, $100^{\circ} \mathrm{C}, 24 \mathrm{~h}$

(c) Panda's work $\left[\left(\mathrm{Im}^{\mathrm{R}} \mathrm{N}\right)_{2} \mathrm{Ti}\left(\mathrm{NMe}_{2}\right)_{2}\right](5 \mathrm{~mol} \%)$, neat, $60^{\circ} \mathrm{C}, 12 \mathrm{~h}$<smiles>[R]Nc1nc2cc[R1]cc2c(=O)n1[R]</smiles>

6 examples 60 to $91 \%$ yield

18 examples 65 to $97 \%$ yield

20 examples 76 to $96 \%$ yield

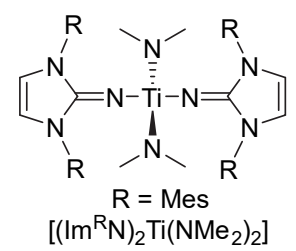

图式 $17 \mathrm{Zn}(\mathrm{OTf})_{2}, \mathrm{La}\left[\mathrm{N}\left(\mathrm{SiMe}_{3}\right)_{2}\right]_{3}$ 和咪唑啉-2-亚氨基钛引发剂催化碳二亚胺的胍化/环化

Scheme $17 \mathrm{Zn}(\mathrm{OTf})_{2}, \mathrm{La}\left[\mathrm{N}\left(\mathrm{SiMe}_{3}\right)_{2}\right]_{3}$ and imidazolin-2-iminato titanium initiator catalyzed guanylation/cyclization

芳基碘鎓盐发生偶联反应形成碳二亚胺阳离子中间体 35, 外部炔烃进一步亲核进攻碳二亚胺产生中间体 36, 其中正电荷可以转移到芳基上以稳定该结构, 最后通过 连续的 Friedel-Crafts 型反应和芳构化获得产物(Scheme 18).
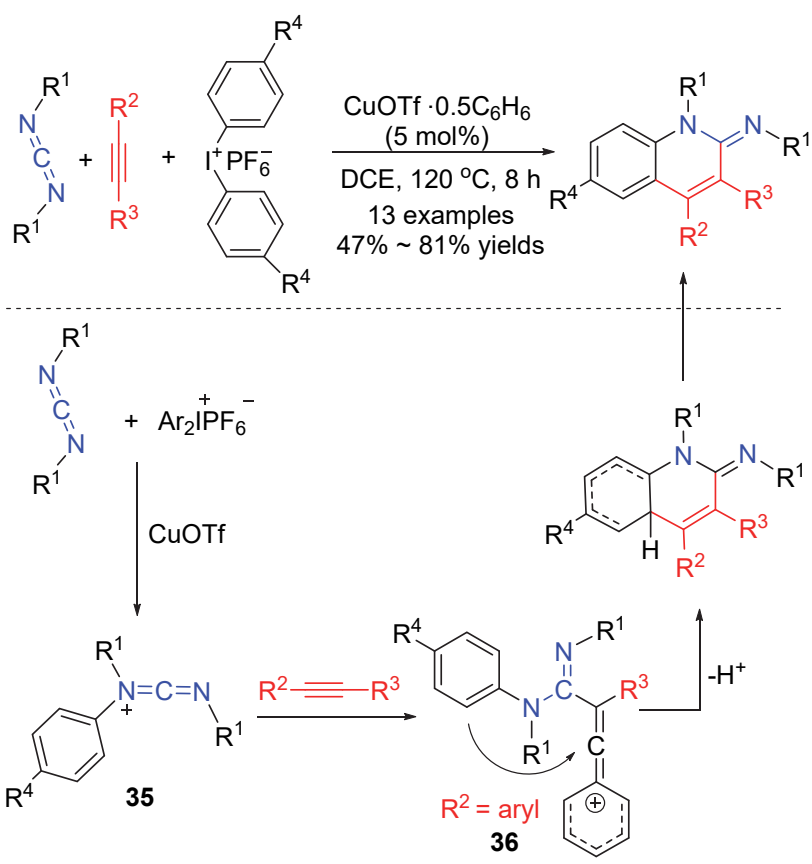

图式 $18 \mathrm{Cu}$ 催化的碳二亚胺、炔烃和二芳基碘鎓盐的串联环 化

Scheme 18 Cu-catalyzed cascade annulation of carbodiimides, alkynes and diaryliodonium salts

最近, Sawant 小组 ${ }^{[26]}$ 报道了一例有趣的 $\operatorname{Pd}(0) /$ $\mathrm{Fe}(\mathrm{III})$ 协同催化环化反应, 可以制备一系列的四唑杂环 分子(Scheme 19). 在 $\mathrm{Pd}\left(\mathrm{PPh}_{3}\right)_{4}$ 的催化下, 芳基叠氮与异 腈发生偶联反应原位生成碳二亚胺; 然后在铁催化剂的
辅助下, $\mathrm{TMSN}_{3}$ 作为亲核试剂, 其中的氮原子进攻碳二 亚胺得到胍基中间体 38, 该中间体再经过电环化生成 氨基四唑产物. 该反应采用 “一锅法” 的方式为四唑衍 生物的合成提供了一种原子经济的策略.

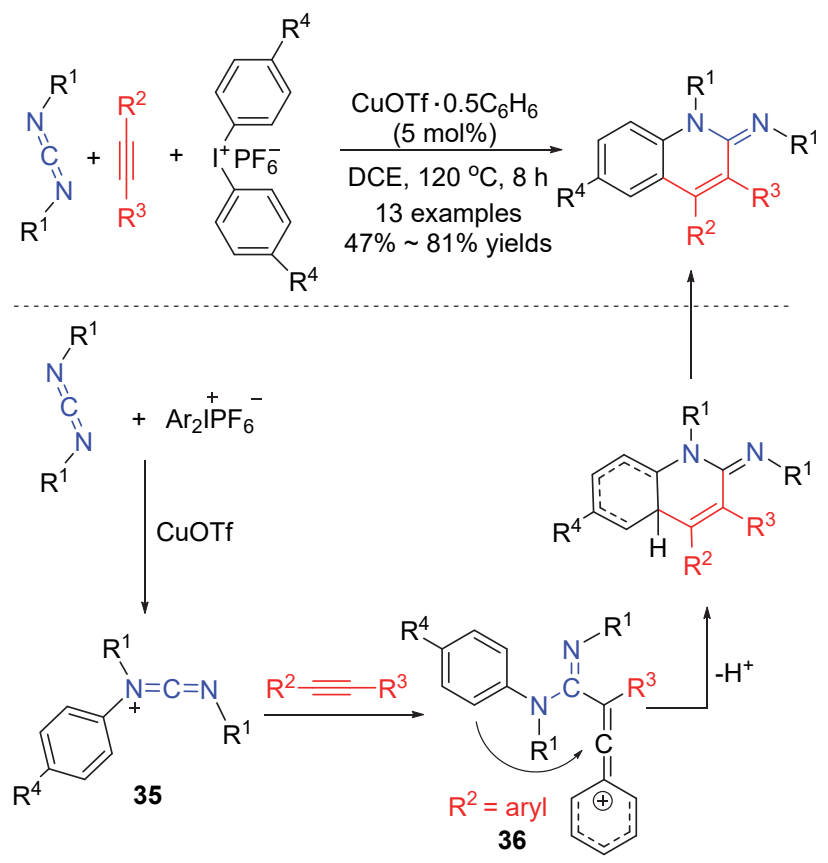

图式 $19 \mathrm{Pd}(0) / \mathrm{Fe}(\mathrm{III})$ 连续催化偶联/环化一锅法合成氨基四 唑

Scheme 19 Sequential $\mathrm{Pd}(0) / \mathrm{Fe}(\mathrm{III})$-catalyzed coupling/cyclization to synthesize aminotetrazoles in one-pot fashion

\section{3 两底物所含官能团均参与的环化反应}

稠合杂环因具有独特的生物学特性和较高的材料 应用价值, 引起了有机合成化学家的广泛关注. 在碳二 亚胺的催化环化反应中, 碳二亚胺和亲核试剂所含官能 
才同时参与的环化过程为构建此类分子提供了有效的 方法. 该策略中，亲核加成中间体在金属催化下，通过 连续的关环过程, 可以快捷高效地合成多种稠合杂环结 构(Scheme 20).

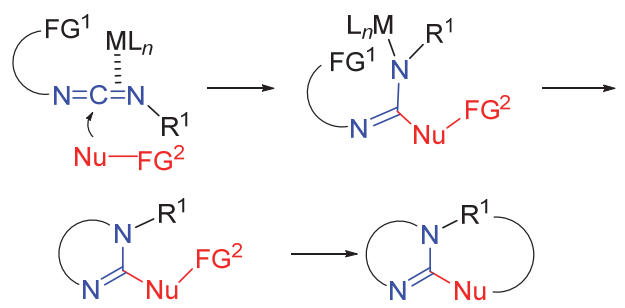

图式 20 两底物所含官能团参与环化反应的基本策略 Scheme 20 Strategy of cascade cyclization with the functional group in both carbodiimide and nucleophile

Alper 小组 ${ }^{[27]}$ 和吴劼小组 ${ }^{[28]}$ 在其前期工作基础上,

(a)<smiles>[R]c1ccc(N=C=Nc2ccc([R])cc2I)c(I)c1</smiles>

分别报道了 $\mathrm{Pd}$ 催化的双邻碘芳基碳二亚胺与胺、 $\mathrm{CO}$ 或 异腈的三组分串联环化反应(Scheme 21). 虽然底物含 有多种官能团，但仍以良好至优异的产率获得了一系列 环稠合喹唑啉酮. 该反应通过巧妙的底物设计, 在 $\mathrm{Pd}$ 催 化的条件下连续发生两次 CO 或异腈的插入反应，一次 性构建五个新化学键和两个杂环. 该方法为氮杂稠合杂 环的快速合成提供了更加高效、便捷的途径.

2012 年，吴劼课题组 ${ }^{[29]}$ 又报道了双邻碘芳基碳二 亚胺与异氰基乙酸酯的 $\mathrm{Cu}$ 催化串联环化反应，以高收 率得到了苯并咪唑并 $[1,5-a$ ]咪唑类化合物. 作者发现对 于含有强吸电子基团的异腈 39, 可以在铜催化的条件 下，经由中间体 $\mathbf{4 0}$ 与双邻碘芳基碳二亚胺发生 $[3+2]$ 环 加成反应得到咪唑类结构 41, 随后经过异构化及 $\mathrm{C}-\mathrm{N}$ 偶联过程生成咪唑并环分子, 该类型产物可通过钯催化 的交叉偶联反应进一步转化(Scheme 22).

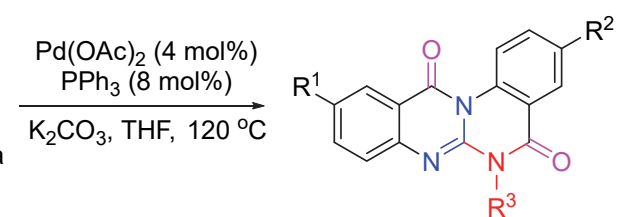

15 examples, up to $89 \%$ yield

(b)<smiles>[R][R]1ccc(N=C=Nc2ccccc2I)c(I)c1</smiles>

$\underset{\mathrm{Cs}_{2} \mathrm{CO}_{3}, \mathrm{PhMe}, \text { reflux }}{\stackrel{\mathrm{Pd}(\mathrm{OAc})_{2}(5 \mathrm{~mol} \%)}{\longrightarrow}}$<smiles></smiles>

15 examples, up to $95 \%$ yield

图式 $21 \mathrm{Pd}$ 催化碳二亚胺与胺、 $\mathrm{CO}$ 或异腈的多组分串联环化反应

Scheme 21 Pd-catalyzed cascade cyclization of carbodiimides, amines with $\mathrm{CO}$ or isocyanides<smiles>[R1]c1ccccc1N=C=Nc1ccccc1I</smiles>

41
$\widehat{R}_{39} \frac{\text { Cul (5 mol\%) }}{\mathrm{K}_{3} \mathrm{PO}_{4}, \text { PhMe, reflux }}$

[Cu] 15 examples, up to $95 \%$ yield<smiles>[R11]c1ccc2c(c1)n(-c1ccccc1[X])c1c([R])ncn21</smiles>

40<smiles>[R]c1cccc([X])c1Nc1c([R])nc(C(Cl)(Cl)Cl)n1-c1ccc[R1]c1I</smiles><smiles>[R][Y11]1ccc(-n2cnc([R])c2Nc2c([R])cccc2[X])c(I)c1</smiles>

图式 $22 \mathrm{Cu}(\mathrm{I})$ 催化的碳二亚胺和异氰基乙酸酯的串联环化反应

Scheme $22 \mathrm{Cu}(\mathrm{I})$-catalyzed tandem reaction of carbodiimides and isocyanoacetates 
2014 年, 吕新课题组 ${ }^{[30]}$ 以双(邻卤代芳基)碳二亚胺 为底物，与不同的 $\mathrm{C}$ 亲核试剂通过 $\mathrm{Cu}$ 催化的连续亲核 环化合成多种稠合杂环分子. 作者研究发现, 以苯并咪 唑为亲核试剂时, 该反应可经过亲核加成、 $\mathrm{Cu}$ 催化分子 内 $\mathrm{C}-\mathrm{N}$ 偶联和分子内 $\mathrm{C}\left(\mathrm{sp}^{2}\right)-\mathrm{H}$ 芳基化过程实现多环 苯并咪唑衍生物的制备(Scheme 23). 当以活性亚甲基 化合物作为亲核试剂时, 在 8-差基喹啉为配体, $\mathrm{K}_{3} \mathrm{PO}_{4}$ 为碱，二甲基亚砜(DMSO)作溶剂的条件下，可以实现 甲基化苯并 $[4,5]$ 咪唑并 $[1,2-a]$ 吲哚的高效合成. 机理上, 在碱的作用下，碳原子进攻碳二亚胺得到脒中间体 $\mathbf{4 3}$, 随后经过连续的 $\mathrm{C}-\mathrm{N}$ 偶联和 $\mathrm{C}-\mathrm{C}$ 偶联过程生成中间 体 45, 最后脱羧异构化得到目标分子(Scheme 24). 由以 上实例可以看出, 过渡金属催化碳二亚胺的环化对于合 成在药物和材料上具有潜在应用价值的稠合氮杂环分 子具有显著的优势.

2016 年, 该课题组 ${ }^{[31]}$ 以易制备的炔丙胺和邻卤代 芳基碳二亚胺为原料, 发展了一例 $\mathrm{Cu}(\mathrm{I})$ 催化的 “多米诺 式” 环化反应, 以优异的区域选择性合成了各种咪唑或 苯并咪唑稠合杂环衍生物. 进一步的机理研究表明, 反 应中的区域选择性是由于亲核加成产物 47 邻近芳环上
的氮负离子比另一端更稳定，更有利于分子内环化，生 成的中间体 48 经过质子解离及 $\mathrm{Cu}$ 催化的 $\mathrm{C}-\mathrm{N}$ 偶联过 程得到目标分子(Scheme 25).

同年，郝文燕课题组 ${ }^{[32}$ 报道了另一例构建稠杂环 的反应. 该研究工作以邻烯基苯基碳二亚胺与异腈为底 物, 在 $\mathrm{Cu}(\mathrm{I})$ 的催化下, 首先经历一个常规的 $[3+2]$ 环加 成, 再发生分子内的共轭环化, 以中等到较高的产率一 步生成多种 4,5-二氢咪唑并 [1,5-a] 喹唑啉衍生物 (Scheme 26).

\section{2 基于碳二亚胺对环金属中间体插入过程的环 化}

过渡金属催化碳二亚胺的插入反应是构建杂环的 另一种重要反应类型. Yamazaki 等[33]在 1977 年对碳二 亚胺与炔烃环加成反应进行了开创性研究, 利用 $\mathrm{Cp}_{2} \mathrm{Co}$ 与炔烃形成的环钴中间体实现碳二亚胺的插入反应，得 到 2-亚氨基-1,2-二氢吡啶化合物. 然而, 该方法需要在 高温及化学计量金属的条件下进行，且对于非对称的炔 烃区域选择性较差，反应以较低产率得到几种环化产物 (Scheme 27，a). 鉴于该类型反应存在的问题和挑战,

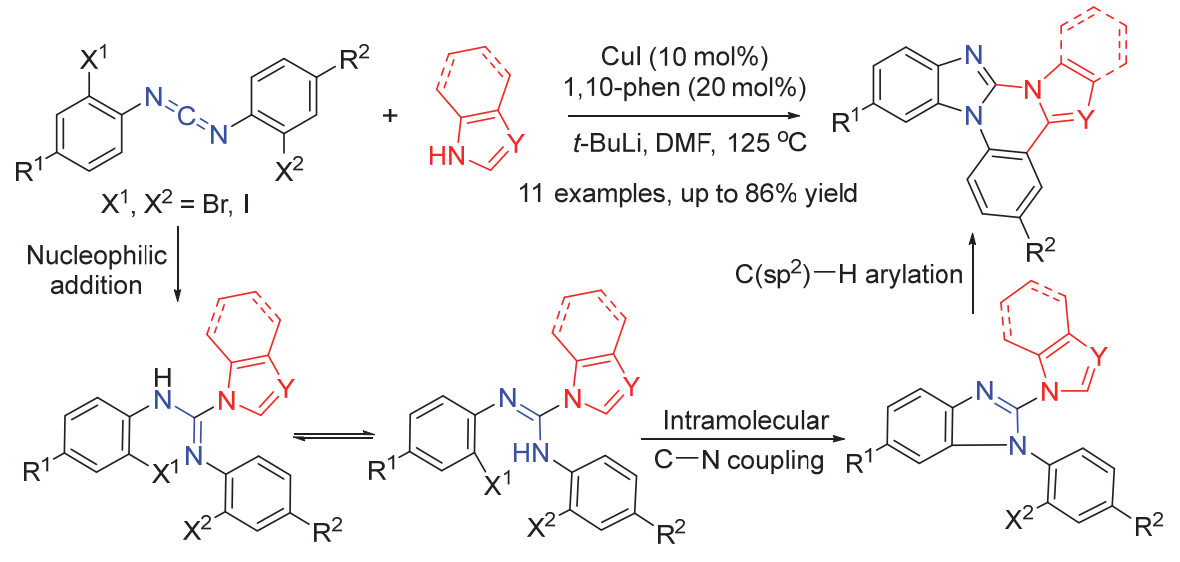

图式 $23 \mathrm{Cu}(\mathrm{I})$ 催化双(邻卤代芳基)碳二亚胺与吡咯衍生物的多米诺反应

Scheme $23 \mathrm{Cu}(\mathrm{I})$-catalyzed domino reaction of bis(o-haloaryl)carbodiimides and azole derivatives

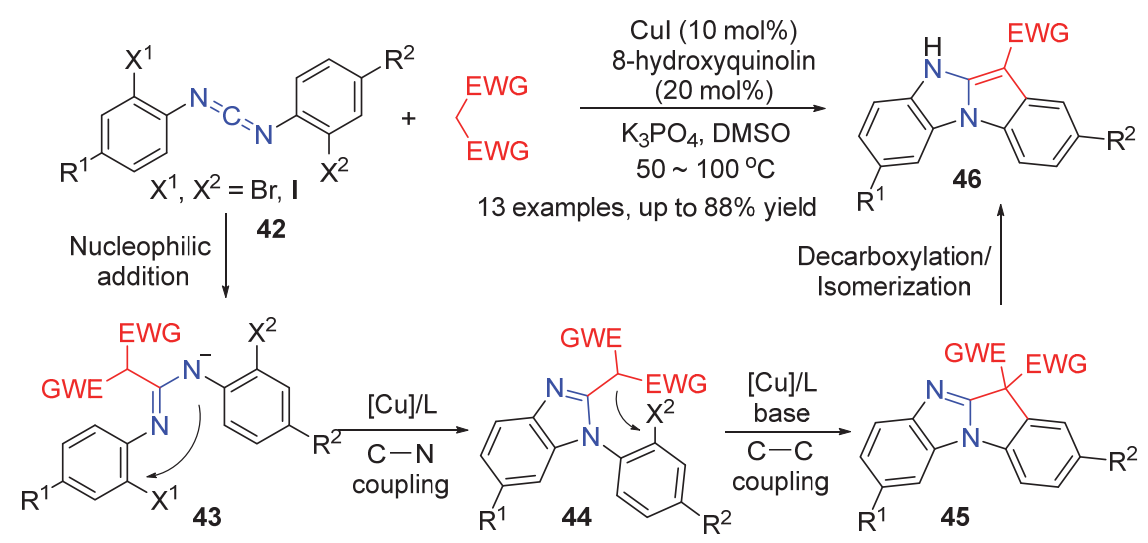

图式 $24 \mathrm{Cu}(\mathrm{I})$ 催化双(邻卤代芳基)碳二亚胺与活性亚甲基化合物的多米诺反应

Scheme $24 \mathrm{Cu}(\mathrm{I})$-catalyzed domino reaction of bis-(o-haloaryl)carbodiimides and active methylene compounds 


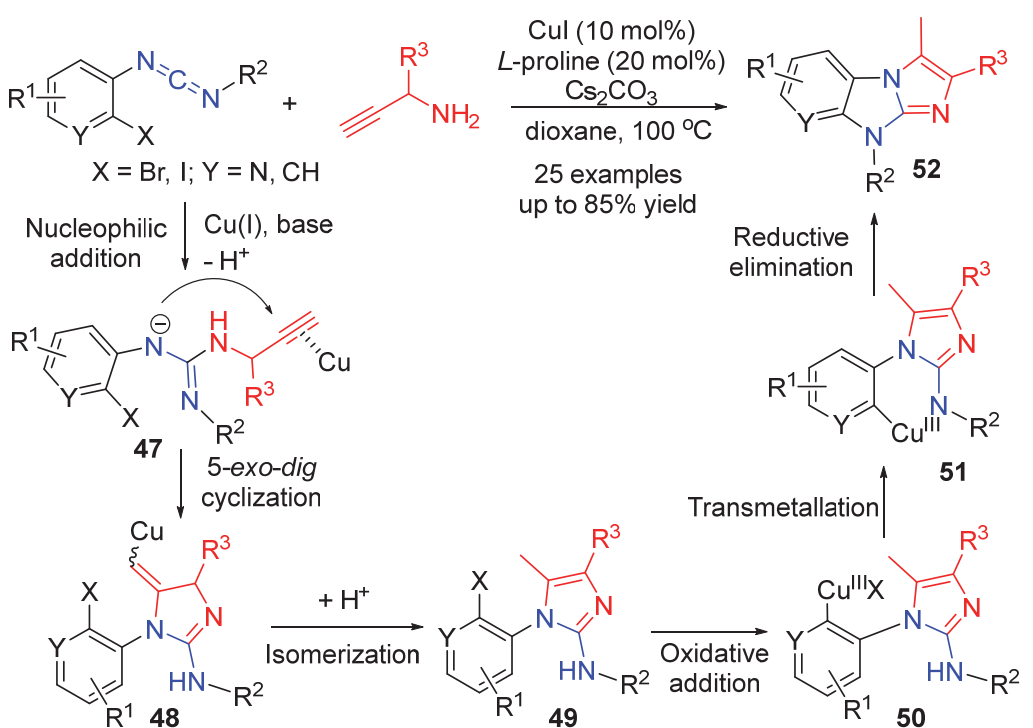

图式 $25 \mathrm{Cu}(\mathrm{I})$ 催化邻卤代芳基碳二亚胺与炔丙基胺的多米诺反应

Scheme $25 \mathrm{Cu}(\mathrm{I})$-catalyzed domino reaction of $o$-haloarylcarbodiimides and propargylic amines

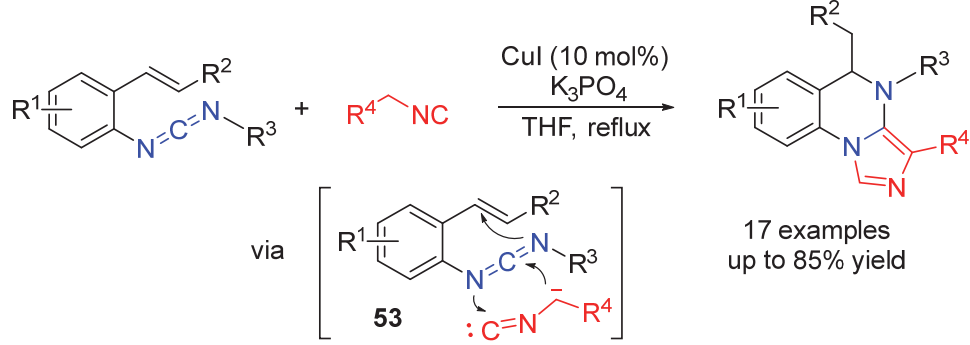

图式 $26 \mathrm{Cu}(\mathrm{I})$ 催化的邻烯基苯基碳二亚胺与异氰酸酯的级联反应

Scheme $26 \mathrm{Cu}(\mathrm{I})$-catalyzed cascade reaction of $o$-alkenylphenyl carbodiimides with isocyanides

(a)<smiles>[R]C#C[R]</smiles>

(b)

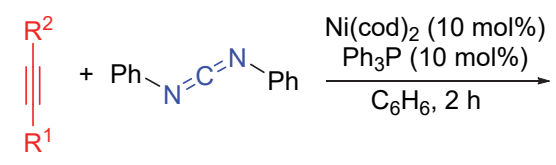<smiles></smiles><smiles>CCc1c(CC)c(CC)n(O)c(=NO)c1CC</smiles>

$93 \%$

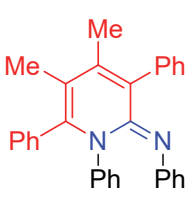

$90 \%$

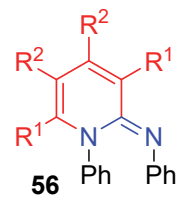

图式 $27 \mathrm{Co}$ 或 Ni 催化二苯基碳二亚胺与炔烃的三聚环化反 应

Scheme 27 Co or Ni-catalyzed cyclotrimerization of acetylenes with carbodiimides
Hoberg 等 ${ }^{[34]}$ 发展了类似的镍催化过程, 仅需较低的催 化剂用量和较低的温度, 就能以优异的收率得到目标产 物, 但对于非对称炔烃该反应仍然存在区域选择性差的 问题(Scheme 27, b).

为了进一步提高反应的化学选择性和区域选择性, 后期的研究选用了键连二炔作为底物. 2007 年, Deiters 小组 ${ }^{[35]}$ 开发了 Co 催化二炔与碳二亚胺的[2+2+2]环三 聚反应. 反应中，二炔负载于聚合物固相载体中，在微 波的作用下，完成碳二亚胺的插入反应，经过三氟乙酸 (TFA)除去保护基团之后，以优异的产率获得了稠合亚 氨基吡啶化合物(Scheme 28). 类似地, Tanaka 研究小 组 ${ }^{[36]}$ 实现了 $\mathrm{Rh}$ 催化的二炔与碳二亚胺的 $[2+2+2]$ 环加 成反应. 对一系列对称和非对称的 1,6-二炔, 都能以中 等至良好的产率得到了相应的环化产物. 反应机理研究 表明: 首先，过渡金属与二炔配位并发生氧化环化得到 金属-环戊二烯中间体 63; 随后碳二亚胺向位阻较小的 $\mathrm{M}-\mathrm{C}$ 键进行区域选择性插入，得到中间体 65 ; 最后还 原消除产生环化产物 61 并使催化剂再生(Scheme 29). 


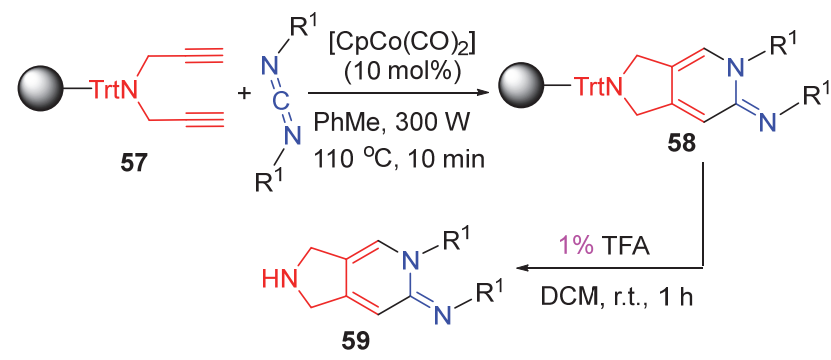

图式 28 Co 催化微波条件下固相合成稠合吡啶环化合物 Scheme 28 Co-catalyzed microwave-mediated solid-supported formation of fused pyridine rings

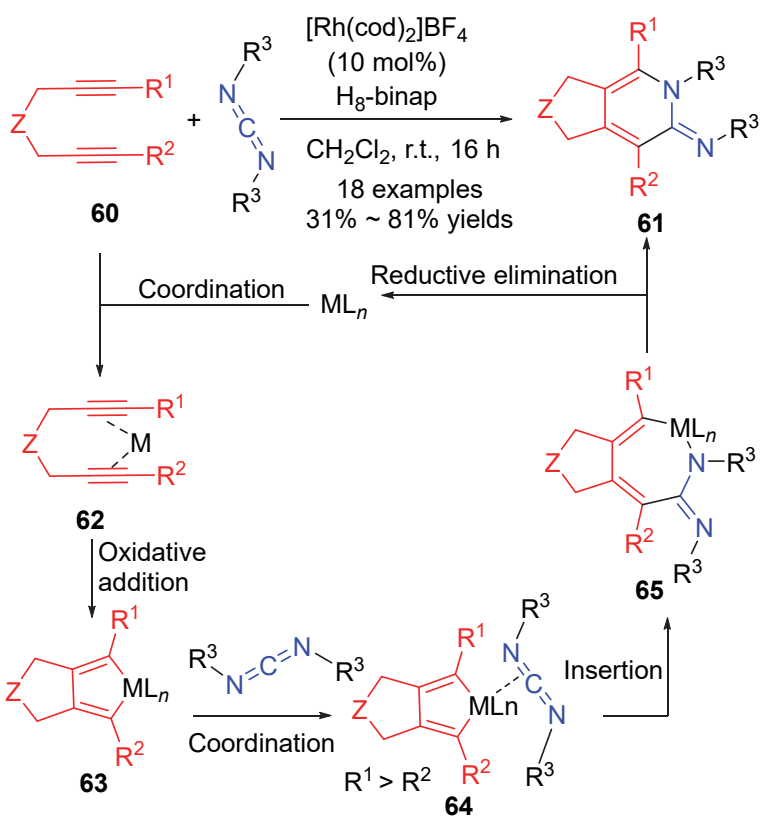

图式 $29 \mathrm{Rh}$ 催化碳二亚胺与二炔的 $[2+2+2]$ 环加成反应

Scheme 29 Rh-catalyzed $[2+2+2]$ cycloaddition of diynes with carbodiimides

随后, Tanaka 课题组 ${ }^{[37]}$ 进一步研究, 发现炔一醛类 底物也可以与碳二亚胺在铑的催化下发生插入环化反 应. 反应以 $\left.\mathrm{Rh}(\mathrm{cod})_{2}\right] \mathrm{BF}_{4} / 1,3$-双 (二苯膦)丙烷 (DPPP)为 催化体系, 在室温条件下通过[4+2]环化反应成功地实 现了 6-亚氨基-2-哌啶酮衍生物的制备. 作者推测反应 机理为: 首先 $\mathrm{Rh}(\mathrm{I})$ 发生氧化加成, 插入醛基的 $\mathrm{C}-\mathrm{H}$ 键 得到中间体 66; 随后与炔烃经过分子内环化得到环酰 基铑中间体 67 , 然后发生碳二亚胺的插入形成环金属 中间体 68; 最后还原消除发生, 释放产物并再生铑催化 剂(Scheme 30).

2017 年, Mathur 等 ${ }^{[38]}$ 报道了一例 $\mathrm{Fe}(\mathrm{CO})_{5}$ 催化的炔 烃、碳二亚胺和 $\mathrm{CO}$ 的三组分环加成反应. 有趣地是, 该 反应可以在光照条件下在较短的时间内完成, 以中等至 较高产率得到 5-亚氨基吡咯烷酮. 反应中, $\mathrm{Fe}(\mathrm{CO})_{5}$ 既是 催化剂又是 $\mathrm{CO}$ 源, 因此需要化学计量的 $\mathrm{Fe}(\mathrm{CO})_{5}$. 对于 反应过程, 作者推测在光解条件下, 首先通过炔烃与两

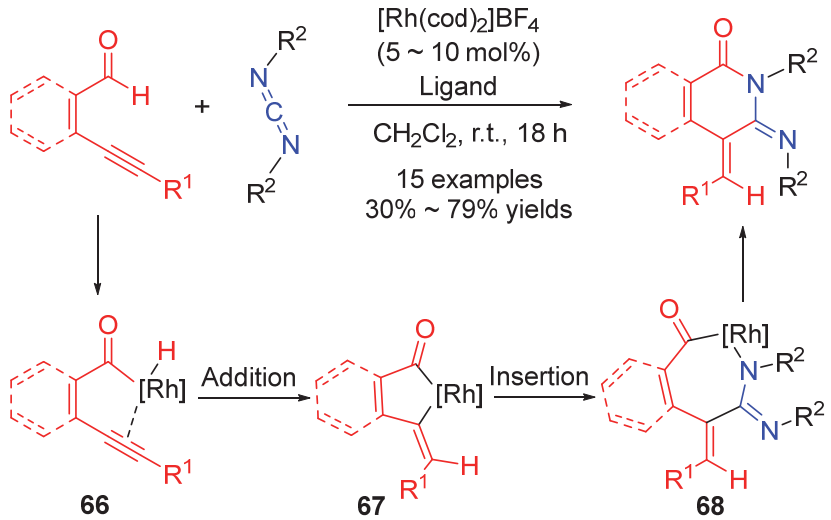

图式 $30 \mathrm{Rh}$ 催化碳二亚胺与 4-炔基醛的 $[4+2]$ 环加成反应 Scheme 30 Rh-catalyzed [4+2] annulations of 4-alkynals with carbodiimides

个 $\mathrm{CO}$ 的环金属化生成四羰基铁中间体 69, 接下来再与 碳二亚胺配位并插入到 $\mathrm{Fe}-\mathrm{C}$ 键中, 得到七元环中间体 71, 随后该中间体释放 $\mathrm{CO}$ 生成更稳定的中间体 72, 最 后还原消除形成所需产物并释放 $\mathrm{Fe}(\mathrm{CO})_{4}$ (Scheme 31).

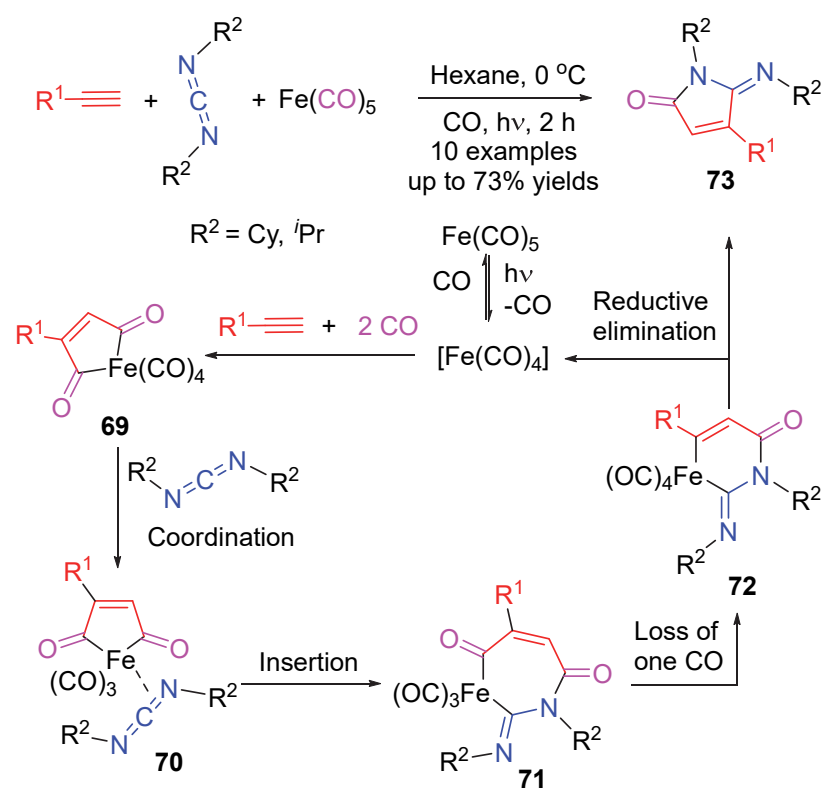

图式 $31 \mathrm{Fe}(\mathrm{CO})_{5}$ 催化碳二亚胺、炔烃和 $\mathrm{CO}$ 的 $[2+2+1]$ 环加 成反应

Scheme $31 \mathrm{Fe}(\mathrm{CO})_{5}$-catalyzed $[2+2+1]$ cycloaddition of alkyne, carbodiimide and $\mathrm{CO}$

最近, 我们课题组 ${ }^{[39]}$ 报道了一例镍催化的碳二亚 胺与靛红酸䣶的脱羧环化反应, 以中等到良好收率获得 二氢喹唑啉酮类化合物. 相比于传统镍催化的插入反 应，该反应中选用较为稳定的 $\mathrm{Ni}(\mathrm{II})$ 为催化剂，通过还 原剂原位生成活性的 $\mathrm{Ni}(0)$, 避免了直接利用对水和空 气敏感的 $\mathrm{Ni}(0)$ 催化剂, 反应操作上更加便捷. 通过系列 的控制实验和 DFT 理论计算, 提出了一种可能的机理 (Scheme 32): 首先原位生成的 $\mathrm{Ni}(0)$ 催化剂与靛红酸酤 
$\mathrm{C}-\mathrm{O}$ 键发生氧化加成得到中间体 74, 该中间体不稳定, 极易脱羧产生相对稳定的环镍物种 75 , 然后经过碳二 亚胺的配位和插入形成环镍中间体 77 , 最后还原消除 生成产物并再生活性 Ni(0)催化剂(Scheme 32).

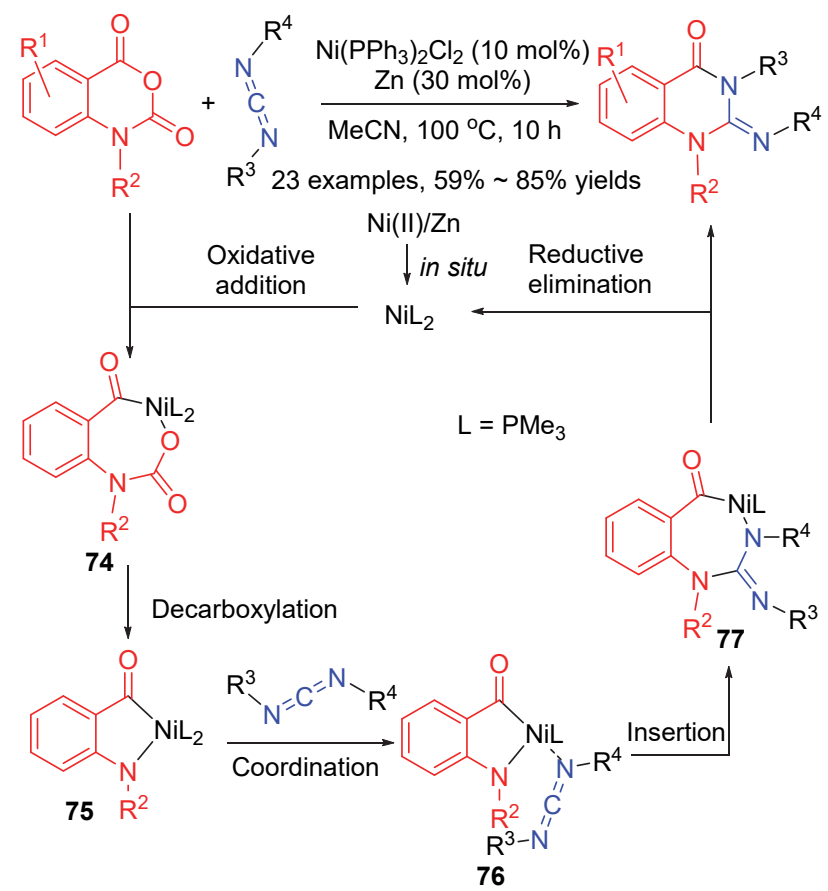

图式 $32 \mathrm{Ni}$ 催化碳二亚胺与靛红酸酐的脱羧环化反应 Scheme 32 Ni-catalyzed decarboxylative cyclization of isatoic anhydrides with carbodiimides

\section{3 含不饱和体系的碳二亚胺参与的协同环化}

含不饱和体系的碳二亚胺参与的催化环化与前两 种类型有所不同, 主要区别在于碳二亚胺先与金属形成 环金属中间体，再经过后续的插入/环化构建杂环分子. 该反应类型的优势是可以自由地修饰碳二亚胺, 通过引 入特定的不饱和底物, 有目的构建杂环. 因此, 该类型 反应在最近十年中引起了广泛的研究兴趣. 本部分根据 取代的碳二亚胺所连不饱和体系类型和环化机理, 分为 烯基碳二亚胺与不饱和体系的环化和炔基碳二亚胺的 Aza-Pauson-Khand 反应两部分.

\section{1 烯基碳二亚胺与不饱和体系的环化}

2008 年, Rovis 小组 ${ }^{[40]}$ 首次报道了烯基碳二亚胺与 炔烃的催化环化. 反应中, 以成烯基碳二亚胺与末端炔 为底物, 在 $R h$ 的催化下实现了对映选择性的 $[2+2+2]$ 环加成反应，通过对手性配体的篮选，以良好对映选择 性得到双环脒类化合物. 机理研究表明, 碳二亚胺与炔 烃首先形成环铑中间体 78, 再实现分子内烯烃的插入 (Scheme 33). 由于该过程是先通过分子间环化形成环 铑中间体, 与该课题组之前报道异氰酸酯的环加成反应
有所不同.

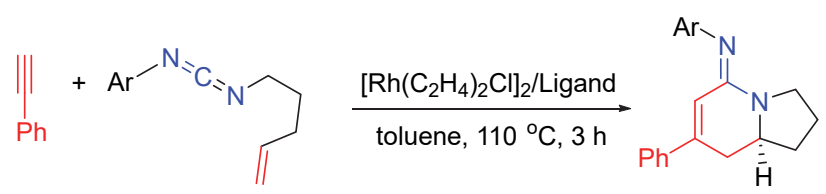

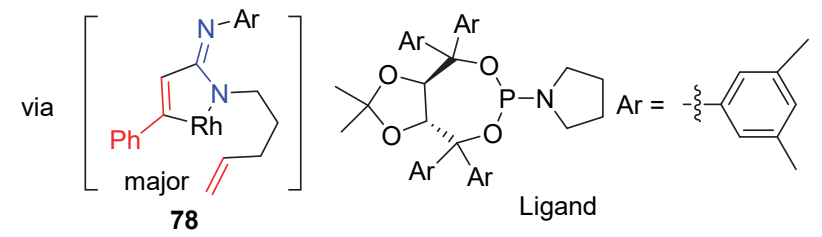

图式 $33 \mathrm{Rh}$ 催化戊烯基碳二亚胺与末端炔的 $[2+2+2]$ 环加 成反应

Scheme 33 Rh-catalyzed $[2+2+2]$ cycloaddition of pentenyl carbodiimides with terminal alkynes

最近, 张振华课题组 ${ }^{[41]}$ 将这种方法扩展到了不饱 和化合物的串联环化. 通过 $\mathrm{Rh}(\mathrm{I})$ 催化叠氮化物与异腈 的快速偶联原位制备乙烯基碳二亚胺，再与炔烃或苯炔 前体发生串联环化，以中等至极好的收率 “一锅法” 合 成了多种氨基吡啶或氨基异喹啉类化合物(Scheme 34). DFT 计算表明, Rh(I)催化剂确实促进了乙烯基碳二亚胺 与炔烃的环化反应. 该课题组 ${ }^{[42]}$ 后续发现第二分子异 腈同样具有与乙烯基碳二亚胺发生环化的能力. 经过系 列条件优化, 实现了 $\mathrm{Rh}$ 催化乙烯基叠氮化物与两分子 异腈的偶联环化反应，这为合成 $N$-取代的 $2 H$-吡咯-2-亚 胺提供了一种简便的方法(Scheme 35). 但是, 机理研究 表明，在第二分子异腈参与的环化中，过渡金属的加入 与否对其影响较小.

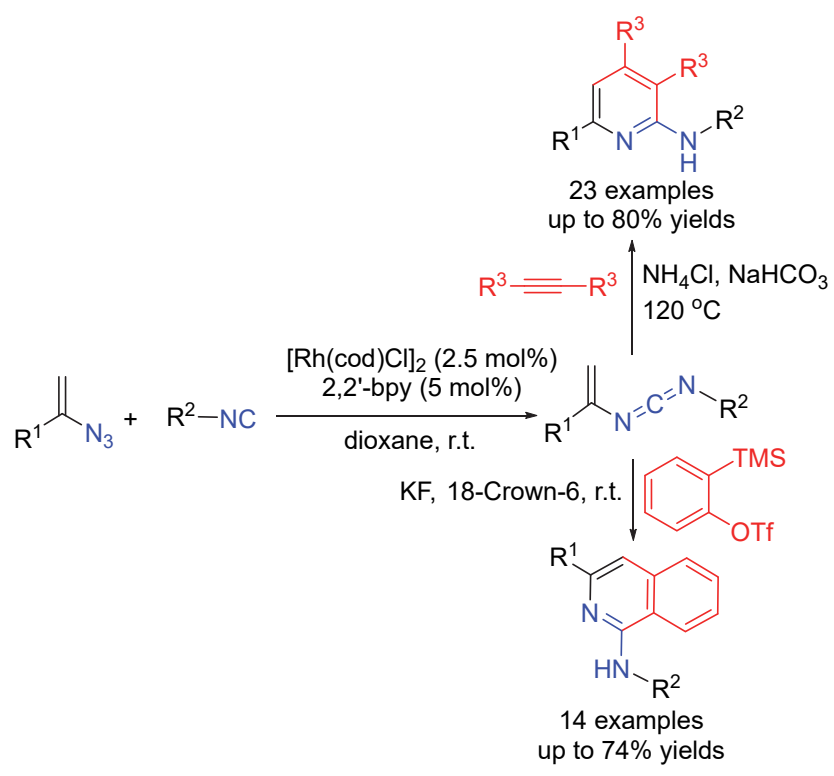

图式 $34 \mathrm{Rh}$ 催化乙烯基叠氮与异腈和炔烃/苯炔的级联反应 Scheme 34 Rh-catalyzed cascade reaction of vinyl azides with isonitriles and alkynes/benzynes 


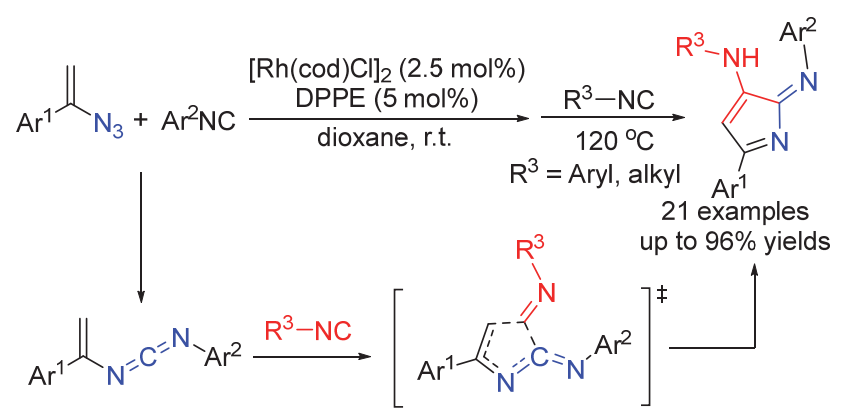

图式 $35 \mathrm{Rh}$ 催化经由乙烯基碳二亚胺中间体的双异腈插入反 应

Scheme 35 Rh-catalyzed double isocyanides insertion via a vinylcarbodiimide intermediate

同年, Takemoto 小组 ${ }^{[43]}$ 利用含有 1,3-二烯基团的碳 二亚胺通过分子内碳硼化反应, 合成具有季碳中心的亚 氨基二氢吲哚化合物. 通过条件优化, 很好地抑制了 $6 \pi$ 电子环化产物的生成(Scheme 36), 该反应先经过关环 碍化生成中间体 79, 再氧化为醇. 应用性研究中, 该反 应被成功地应用于含有甲氧基, 对硝基苯磺酰基 $(p \mathrm{Ns})$ 和苠氧羰基 $(\mathrm{Cbz})$ 基团的多取代底物的转化, 生成的亚 氨基二氢吲哚经过后续转化, 可以制备稠合杂环化合物

80.
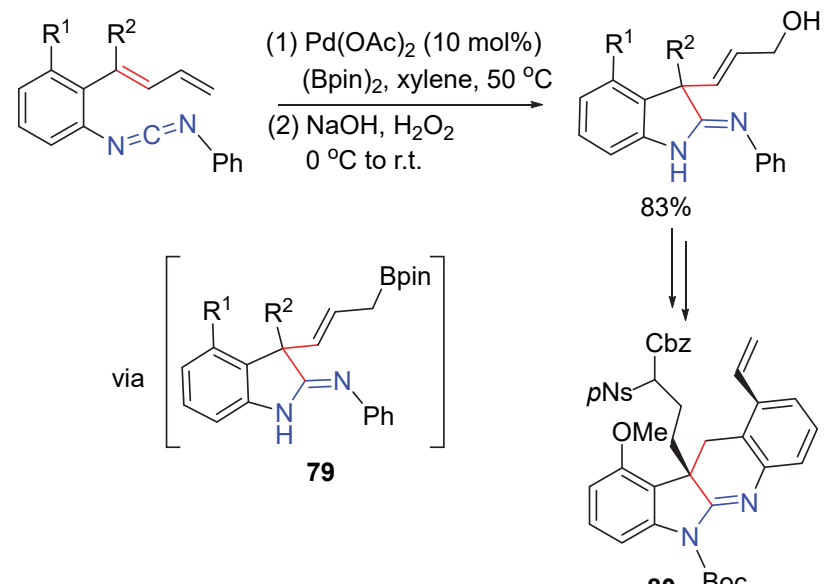

80 Boc

图式 $36 \mathrm{Pd}$ 催化含 1,3-二烯碳二亚胺的分子内碳硼环化反应 Scheme 36 Pd-catalyzed intramolecular carboborylation of carbodiimides bearing 1,3-diene

\section{2 炔基碳二亚胺的 Aza-Pauson-Khand 反应}

Pauson-Khand 反应是构建多并环结构的最有效方 法之一. 炔基碳二亚胺由于同时具有 $\mathrm{C} \equiv \mathrm{C}$ 和 $\mathrm{C}=\mathrm{N}$, 在 过渡金属的作用下, 可以与 $\mathrm{CO}$ 、异腈或炔烃等不饱和 结构发生氮杂-Pauson-Khand 反应, 合成一系列具有重 要意义的多并杂环分子. 以 $\mathrm{CO}$ 参与的反应为例, 常规 的催化循环如 Scheme 37 所示: 过渡金属首先通过 $\pi$ 络 合与炔基碳二亚胺配位，随后的氧化环金属化生成物种
83 同时构建新的 $\mathrm{C}-\mathrm{C}$ 键，然后 $\mathrm{CO}$ 插入到环金属中间 体 83 的 $\mathrm{M}-\mathrm{C}$ 键中得到金属络合物 84 , 最后还原消除 释放最终产物并再生催化剂.

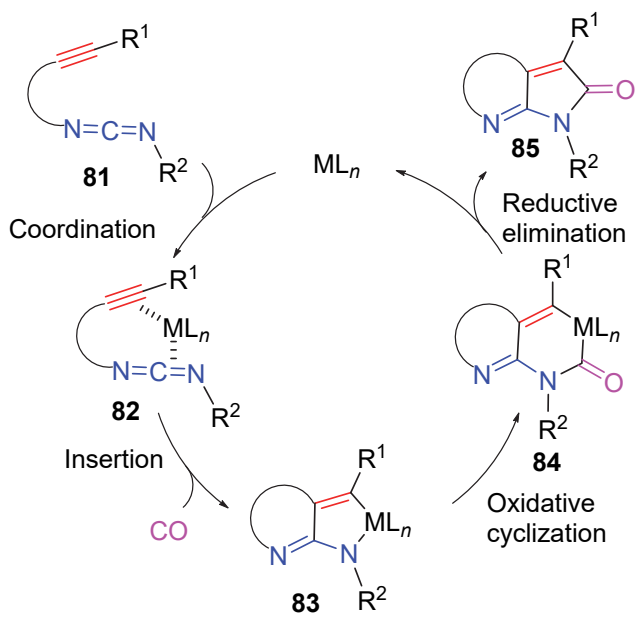

图式 37 炔基碳二亚胺与 $\mathrm{CO}$ 的 Aza-Pauson-Khand 反应的基 本过程

Scheme 37 General process of catalytic Aza-Pauson-Khand reaction of alkyne carbodiimide with $\mathrm{CO}$

该类型反应是由 Saito 研究小组 ${ }^{[44]}$ 在 2003 年首次报 道，通过炔基碳二亚胺与 CO 的 $a z a$-Pauson-Khand 反应， 合成了吡咯并一吲哚酮和吡咯并一吡咯啉酮两类重要的 杂环 $\left(\right.$ Scheme 38, a). 由于反应中 $\mathrm{Mo}(\mathrm{CO})_{6}$ 既是催化剂又 是 CO 源, 因此需要化学计量的金属催化剂完成反应. 2007 年，该小组 ${ }^{[45]}$ 开发了一种催化的 $a z a$-Pauson-Khand 反应，在铑催化下，炔基碳二亚胺与 $\mathrm{CO}(101 \mathrm{kPa})$ 以中 等至良好的收率完成环化反应，而且一系列烷基和芳基 取代的碳二亚胺均表现出较好的兼容性(Scheme 38, b). 在 Saito 小组报道铑催化的反应之前, Mukai 等 ${ }^{[46]}$ 开发了 一种类似的环化过程, 该反应在 $\mathrm{CO}$ 气氛下利用催化量 的 $\mathrm{Co}_{2}(\mathrm{CO})_{8}$ 作为催化剂, 高效地获得了一系列吡咯并 [2,3-b]吲哚-2-酮杂环分子. 重要地是, 作者将该方法成

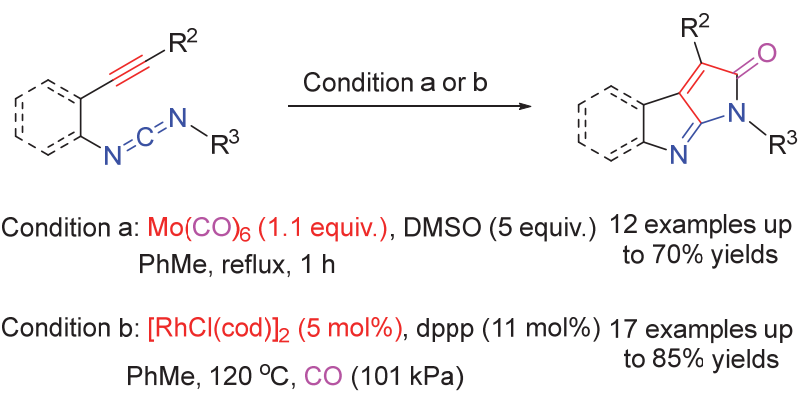

图式 38 过渡金属参与的分子内炔基碳二亚胺的 PausonKhand 型反应

Scheme 38 Transition-metal-mediated intramolecular alkynecarbodiimide Pauson-Khand-type reaction 
功地应用于天然产物 $( \pm)$-毒扁豆碱的合成, 并获得了较 好的立体选择性(Scheme 39).
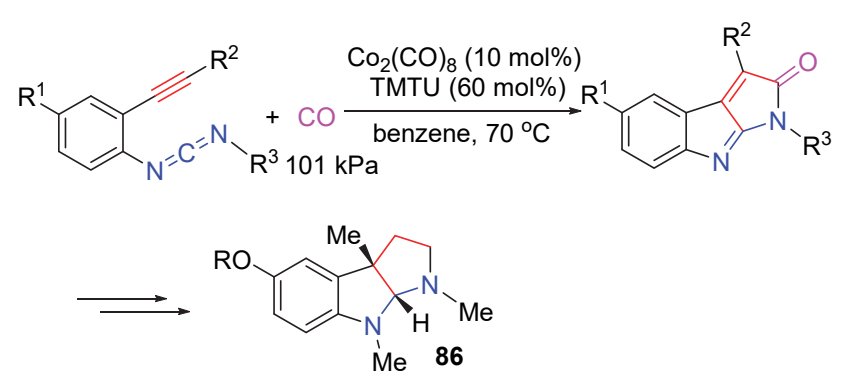

Esermethole: $\mathrm{R}=\mathrm{Me}$

Physostigmine: $\mathrm{R}=\mathrm{C}(\mathrm{O}) \mathrm{NHMe}$

图式 $39 \mathrm{Co}_{2}(\mathrm{CO})_{8}$ 催化炔基碳二亚胺的分子内 Pauson-Khand 型反应合成 $( \pm)$-毒扁豆碱

Scheme $39 \mathrm{Co}_{2}(\mathrm{CO})_{8}$-catalyzed intramolecular Pauson-Khandtype reaction of alkyne carbodiimide for the synthesis of $( \pm)$ physostigmine

接下来的几年中, Saito 研究小组一直致力于研究炔 基碳二亚胺参与的 $a z a$-Pauson-Khand 反应. 在 2010 年, 该小组 ${ }^{[47]}$ 将炔基碳二亚胺底物范围扩展到了含有苄基 碳中心的 $N$-[2-(2-炔基-1-基)苯基]碳二亚胺(Scheme 40). 有趣地是, 通过 $\mathrm{Rh}(\mathrm{I})$ 催化的分子内环化反应, 该底物可 以转化为多种吡咯并[2,3- $b$ 喹啉类杂环, 其反应催化循 环与先前报道的相似, 只是由于底物的区别可以得到六 并五的杂环结构. 除了与 CO 环化, 该小组尝试用炔烃 替代 CO, 使催化循环发生炔烃插入. 基于此策略, 开发 了 $\mathrm{Rh}(\mathrm{I})$ 催化 $N, N^{\prime}$-双-[2-(2-炔基-1-基)苯基]碳二亚胺或 其萗类似物的 $[2+2+2]$ 环加成反应, 以制备具有吡咯 并 $[1,2-a][1,8]$-菜啶单元的多环 L 形化合物(Scheme $41)^{[48-49]}$. 这些 L 形化合物可以以高量子产率发射苂光, 通过对不同底物菼光效果的研究, 发现取代基位置的改 变使 $\mathrm{L}$ 形化合物发出多种颜色的苂光并表现出溶剂化<smiles>[R]C#CC([R1])c1ccccc1N=C=N[R]</smiles><smiles>[R]c1c2c(nc3ccccc13)N([R]C)C(=O)C2[R]</smiles>
$33 \% \sim 85 \%$ yields via<smiles>[R]c1c2c(nc3ccccc13)N([R1])[P+](C)(C)C2[R]</smiles>

图式 $40 \mathrm{Rh}(\mathrm{I})$ 催化炔基碳二亚胺的 Pauson-Khand 型反应合成 吡咯并 $[2,3-b]$ 喹啉

Scheme $40 \mathrm{Rh}(\mathrm{I})$-catalyzed Pauson-Khand-type reaction of alkyne carbodiimide to synthesize pyrrolo[2,3-b]quinolines

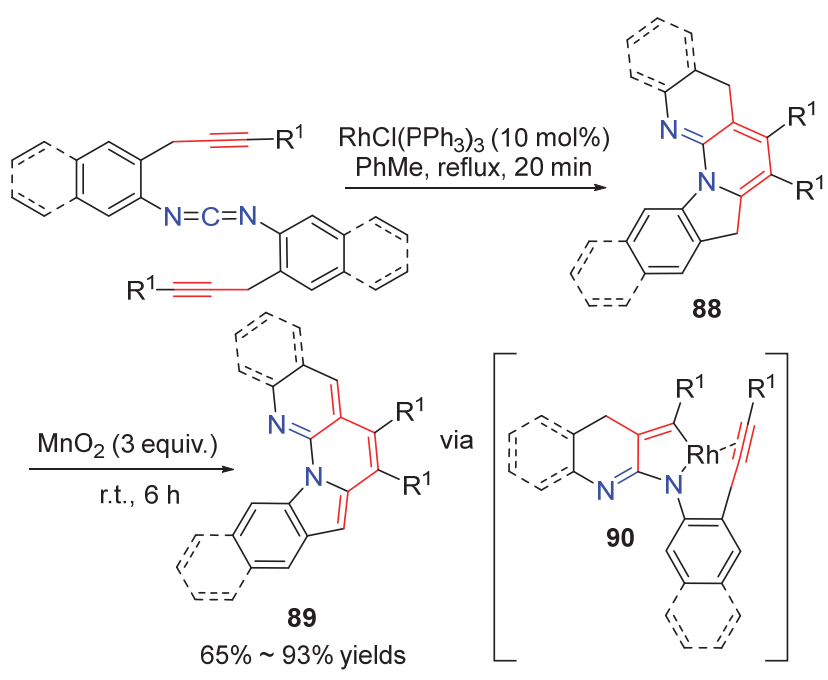

图式 $41 \mathrm{Rh}(\mathrm{I})$ 催化双(炔丙基苯基)-碳二亚胺的分子内 $[2+$ $2+2]$ 环加成

Scheme $41 \mathrm{Rh}(\mathrm{I})$-catalyzed intramolecular $[2+2+2]$ cycloaddition of bis(propargylphenyl)-carbodiimides

效应. 进一步循环伏安法研究和 DFT 计算表明, 最高己 占分子轨道(HOMO)和最低空分子轨道(LUMO)的能级 主要取决于含吡咯和吡啶一侧的体系.

这项工作之后，该小组 ${ }^{[50]}$ 发现在没有 $\mathrm{CO}$ 的情况下， 含有茮基碳中心的 $N$-[2-(2-炔基-1-基)苯基]碳二亚胺的 环化过程将通过 Rh(I)催化的 “烯型” 环异构化进行, 得 到 3-(顺式-烯-1-基)-2-氨基喹啉类产物. 转化过程如 Scheme 42 所示: 炔基碳二亚胺与铑经过配位和氧化环

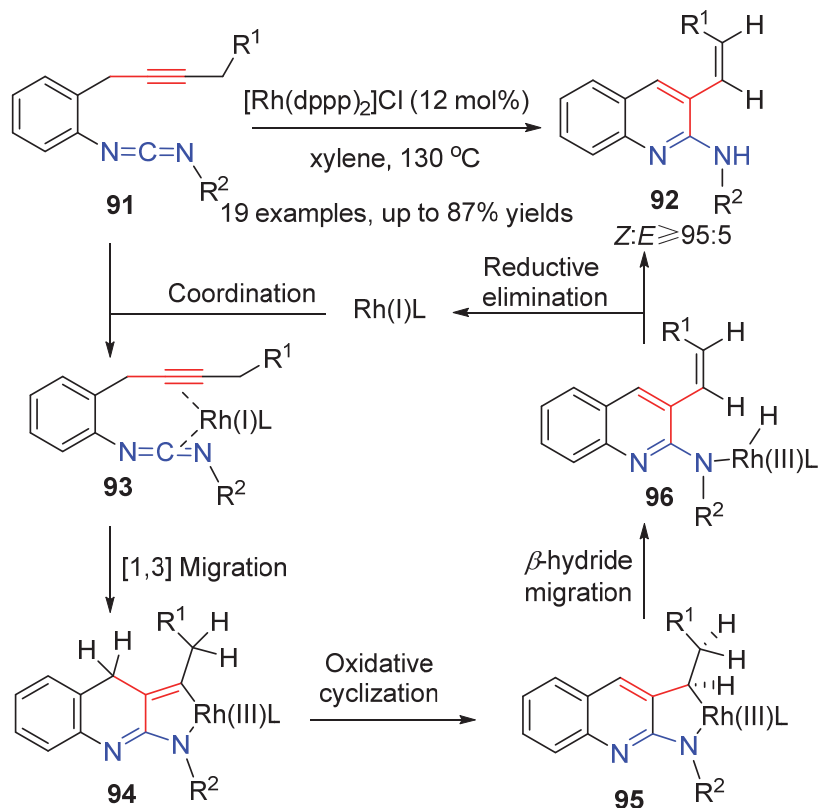

图式 $42 \mathrm{Rh}(\mathrm{I})$ 催化的 $N$-[2-(2-炔-1-基)苯基]碳二亚胺的 “烯 型”环异构化

Scheme $42 \mathrm{Rh}(\mathrm{I})$-catalyzed "ene-type" cycloisomerization of $N$-[2-(2-alkyn-1-yl)phenyl] carbodiimides 
化后, 由于没有 $\mathrm{CO}$, 芐基质子发生[1,3]迁移形成更稳 定的中间体 95, 氢化物向铑的迁移导致立体选择性地 形成顺式烯基喹啉, 最后经过 $\mathrm{B}-\mathrm{H}$ 消除得到所需产物 并再生催化剂.

2016 年, 张振华课题组 ${ }^{[51]}$ 通过原位生成炔基碳二 亚胺, 开发了一例 $\mathrm{Rh}(\mathrm{I})$ 催化叠氮与异腈或 $\mathrm{CO}$ 的多组分 环化反应, 生成两种基于吡咯并 $[2,3-b]$ 吲哚化合物. 该 反应分为两部分, 首先通过 $\mathrm{Rh}$ 催化叠氮与异腈偶联原 位生成炔基碳二亚胺, 然后经过 $a z a$-Pauson-Khand 反应 分别与 CO 或异腈发生环化(Scheme 43), 将具有叠氮基 团的三个不饱和片段经济地组装成杂环结构. 此外, 作 者还对异腈和 $\mathrm{CO}$ 与叠氮化物在同一偶联反应中的反应 活性进行了研究, 发现异腈比其等电子体 CO 拥有更高 的反应活性.
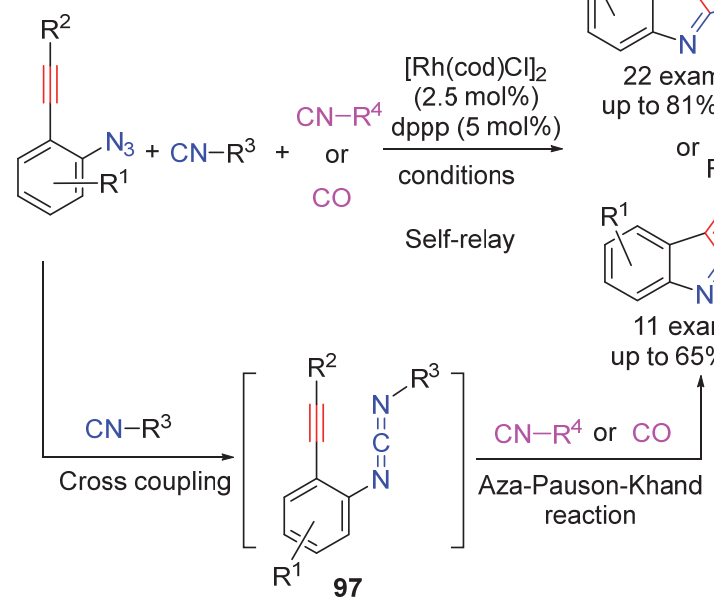

图式43 $\mathrm{Rh}(\mathrm{I})$ 连续催化炔基叠氮与两分子 $\sigma$ 供体 $/ \pi$ 受体(异腈 或 $\mathrm{CO}$ )的串联环化反应

Scheme 43 Self-relay $\mathrm{Rh}(\mathrm{I})$-catalyzed cyclization of alkyne-azides with two $\sigma$-donor $/ \pi$-acceptor (isonitriles or $\mathrm{CO}$ )

\section{4 结论与展望}

综上所述, 过渡金属催化的碳二亚胺环化已成为合 成含氮杂环的快速有效方法. 对于反应过程, 虽然亲核 加成引发的环化仍是构建各类杂环的主要途径, 但碳二 亚胺的环金属插入过程和不饱和体系协同环化过程在 稠环的构建中显示出了独特的优势, 更令人欣喜的是, 在大多数转化中, 非对称碳二亚胺的区域选择性得到了 很好的控制. 虽然该领域已经取得了不错的进展, 但仍 存在一些亟需解决的问题: (1)对于碳二亚胺的环金属插 入反应类型, 主要适用对象为对称的碳二亚胺, 对于非 对称底物的拓展仍需进一步研究; (2)除了传统的亲核和 插入等反应机理, 涉及碳二亚胺的新环化模式(如自由
基过程)还需进一步探索(例如，可以尝试使用碳二亚胺 捕获碳自由基的方式构建环状分子); (3)从绿色和可持 续化学的角度看, 在未来研究中, 可尝试将可见光诱导 反应模式应用到碳二亚胺的环化反应中，以更温和的方 式构建杂环分子. 总之, 鉴于氮杂环在生物活性分子和 药物中的普遍性和重要性，毫无疑问，在未来几年中， 越来越多基于碳二亚胺的催化环化方法和有趣的杂环 结构将不断出现.

\section{References}

[1] (a) Vovk, M. V.; Samarai, L. I. Russ. Chem. Rev. 1992, 61, 297. (b) Williams, A.; Ibrahim, I. T. Chem. Rev. 1981, 81, 589.

(c) Ulrich, H. Chemistry and Technology of Carbodiimides, John Wiley \& Sons, Ltd, Chichester, UK, 2007.

[2] (a) Zhang, W. X.; Hou, Z. Org. Biomol. Chem. 2008, 6, 1720. (b) Alonso-Moreno, C.; Antinolo, A.; Carrillo-Hermosilla, F.; Otero, A. Chem. Soc. Rev. 2014, 43, 3406.

(c) Xu, L.; Zhang, W.-X.; Xi, Z. Organometallics 2015, 34, 1787.

(d) Zhang, W.-X.; Xu, L.; Xi, Z. Chem. Commun. 2015, 51, 254.

(e) Wang, L.; Chi, Y.; Zhang, W.; Xi, Z. Chin. J. Org. Chem. 2018, 38,1341 (in Chinese).

(王连军, 迟栰, 张文雄, 席振峰, 有机化学, 2018, 38, 1341.)

[3] Peshkov, V. A.; Pereshivko, O. P.; Nechaev, A. A.; Peshkov, A. A.; Van der Eycken, E. V. Chem. Soc. Rev. 2018, 47, 3861.

[4] Wang, Y.; Zhang, W. X.; Xi, Z. Chem. Soc. Rev. 2020, 49, 5810.

[5] Lv, X.; Bao, W. J. Org. Chem. 2009, 74, 5618.

[6] (a) Evindar, G.; Batey, R. A. Org. Lett. 2003, 5, 133.

(b) Yang, T.; Lin, C.; Fu, H.; Jiang, Y.; Zhao, Y. Org. Lett. 2005, 7, 4781 .

[7] He, H.-F.; Wang, Z.-J.; Bao, W. Adv. Synth. Catal. 2010, 352, 2905.

[8] Huang, N. Y.; Liu, M. G.; Ding, M. W. J. Org. Chem. 2009, 74, 6874.

[9] Lin, Y.; Li, E.; Wu, X.; Wang, L.; Wang, H.; Li, X.; Kang, H.; Zhou, L.; Shen, G.; Lv, X. Org. Biomol. Chem. 2020, 18, 1476.

[10] (a) Wu, X.-F.; Neumann, H.; Beller, M. Chem. Rev. 2012, 113, 1. (b) Chen, J. R.; Hu, X. Q.; Lu, L. Q.; Xiao, W. J. Chem. Rev. 2015, $115,5301$.

[11] Zeng, F.; Alper, H. Org. Lett. 2010, 12, 1188.

[12] (a) Domling, A. Chem. Rev. 2006, 106, 17.

(b) Lygin, A. V.; de Meijere, A. Angew. Chem., Int. Ed. 2010, 49, 9094.

[13] Qiu, G.; Liu, G.; Pu, S.; Wu, J. Chem. Commun. 2012, 48, 2903.

[14] Qiu, G.; Lu, Y.; Wu, J. Org. Biomol. Chem. 2013, 11, 798.

[15] Larksarp, C.; Alper, H. J. Org. Chem. 1998, 63, 6229.

[16] (a) Butler, D. C.; Inman, G. A.; Alper, H. J. Org. Chem. 2000, 65, 5887.

(b) Zhou, H.-B.; Alper, H. Tetrahedron 2004, 60, 73.

[17] Wang, F.; Cai, S.; Liao, Q.; Xi, C. J. Org. Chem. 2011, 76, 3174

[18] Shen, G.; Bao, W. Adv. Synth. Catal. 2010, 352, 981.

[19] Duangjan, C.; Rukachaisirikul, V.; Saithong, S.; Kaeobamrung, J. Tetrahedron Lett. 2018, 59, 3537.

[20] Han, M.-S.; Hahn, H.-G. Bull. Korean Chem. Soc. 2012, 33, 1371.

[21] Larksarp, C.; Alper, H. J. Org. Chem. 2000, 65, 2773.

[22] Chi, Y.; Xu, L.; Du, S.; Yan, H.; Zhang, W. X.; Xi, Z. Chem.-Eur. J. 2015, 21, 10369 .

[23] Lu, C.; Gong, C.; Zhao, B.; Hu, L.; Yao, Y. J. Org. Chem. 2018, 83, 1154.

[24] Das, S.; Bhattacharjee, J.; Panda, T. K. Dalton Trans. 2019, 48, 7227.

[25] Chi, Y.; Yan, H.; Zhang, W. X.; Xi, Z. Org. Lett. 2017, 19, 2694.

[26] Pathare, R. S.; Ansari, A. J.; Verma, S.; Maurya, A.; Maurya, A. K.; Agnihotri, V. K.; Sharon, A.; Pardasani, R. T.; Sawant, D. M. J. Org. Chem. 2018, 83, 9530. 
[27] Zeng, F.; Alper, H. Org. Lett. 2010, 12, 3642.

[28] Qiu, G.; He, Y.; Wu, J. Chem. Commun. 2012, 48, 3836.

[29] Qiu, G.; Wu, J. Chem. Commun. 2012, 48, 6046.

[30] Yuan, G.; Liu, H.; Gao, J.; Yang, K.; Niu, Q.; Mao, H.; Wang, X.; Lv, X. J. Org. Chem. 2014, 79, 1749

[31] Xu, B.; Peng, B.; Cai, B.; Wang, S.; Wang, X.; Lv, X. Adv. Synth. Catal. 2016, 358, 653 .

[32] Hao, W.; Sang, X.; Xiao, Y.; Cai, M. Tetrahedron Lett. 2016, 57, 4207.

[33] Hong, P.; Yamazaki, H. Tetrahedron Lett. 1977, 18, 1333.

[34] Hoberg, H.; Burkhart, G. Synthesis 1979, 1979, 525.

[35] Young, D. D.; Deiters, A. Angew. Chem., Int. Ed. 2007, 46, 5187.

[36] Ishii, M.; Mori, F.; Tanaka, K. Chem.-Eur. J. 2014, 20, 2169.

[37] Tanaka, K.; Mimura, M.; Hojo, D. Tetrahedron 2009, 65, 9008.

[38] Raghuvanshi, A.; Singh, A. K.; Mobin, S. M.; Mathur, P. ChemistrySelect 2017, 2, 9245.

[39] Zhang, Z.; Qin, Z.; Chang, W.; Li, J.; Fan, R.; Wu, X.; Guo, R.; Xie, X.; Zhou, L. Adv. Synth. Catal. 2020, 362, 2864.

[40] Lee, E. E.; Rovis, T. Org. Lett. 2008, 10, 1231.

[41] Li, Z.; Huo, T.; Li, L.; Feng, S.; Wang, Q.; Zhang, Z.; Pang, S.; Zhang, Z.; Wang, P.; Zhang, Z. Org. Lett. 2018, $20,7762$.
[42] Wang, Y.; Li, Z.; Zhao, H.; Zhang, Z. Synthesis 2019, 51, 3250.

[43] Tsukano, C.; Nakajima, M.; Hande, S. M.; Takemoto, Y. Org. Biomol. Chem. 2019, 17, 1731.

[44] Saito, T.; Shiotani, M.; Otani, T.; Hasaba, S. Heterocycles 2003, 60.

[45] Saito, T.; Sugizaki, K.; Otani, T.; Suyama, T. Org. Lett. 2007, 9 , 1239.

[46] Mukai, C.; Yoshida, T.; Sorimachi, M.; Odani, A. Org. Lett. 2006, 8,83 .

[47] Saito, T.; Furukawa, N.; Otani, T. Org. Biomol. Chem. 2010, 8, 1126.

[48] Otani, T.; Saito, T.; Sakamoto, R.; Osada, H.; Hirahara, A.; Furukawa, N.; Kutsumura, N.; Matsuo, T.; Tamao, K. Chem. Commun. 2013, 49, 6206

[49] Tateno, K.; Ogawa, R.; Sakamoto, R.; Tsuchiya, M.; Kutsumura, N.; Otani, T.; Ono, K.; Kawai, H.; Saito, T. J. Org. Chem. 2018, 83, 690.

[50] Otani, T.; Onishi, M.; Seino, T.; Furukawa, N.; Saito, T. RSC Adv. 2014, 4, 53669.

[51] Zhang, Z.; Xiao, F.; Huang, B.; Hu, J.; Fu, B.; Zhang, Z. Org. Lett. 2016, 18,908 .

(Zhao, C.) 